\title{
DIRECT STRENGTH PREDICTION OF LIPPED CHANNEL COLUMNS EXPERIENCING LOCAL-PLATE/DISTORTIONAL INTERACTION
}

\author{
N. Silvestre, D. Camotim* and P.B. Dinis \\ Department of Civil Engineering and Architecture, ICIST/IST, Technical University of Lisbon, Portugal \\ *(Corresponding author: E-mail: dcamotim@civil.ist.utl.pt)
}

Received: 9 November 2007; Revised: 3 January 2008; Accepted: 7 January 2008

\begin{abstract}
This paper reports an ongoing investigation intended to assess the performance of the Direct Strength Method (DSM) to estimate the ultimate strength of lipped channel columns affected by local-plate/distortional mode interaction. First, the DSM approaches to safety check columns against local-plate and distortional failures are briefly reviewed, with special attention devoted to a recently proposed extension that takes into account the above buckling mode interaction. Next, one presents and discusses the results of a parametric study, carried out by means of the code ABAQUS and involving the evaluation of the "exact" ultimate loads of 63 lipped channel columns with various geometries, all exhibiting local-plate/distortional interaction. Then, these ultimate strength data are compared with the estimates provided by the available DSM formulae and, on the basis of this comparison, one identifies several features that a DSM approach successfully accounting for local-plate/distortional interaction must incorporate.
\end{abstract}

Keywords: Direct Strength Method (DSM), cold-formed steel, lipped channel columns, strength, local-plate buckling, distortional buckling, local-plate/distortional interaction

\section{INTRODUCTION}

The Direct Strength Method (DSM) was originally proposed by Schafer and Peköz [1], about nine years ago, and has been continuously improved since, mainly due to the research activity carried out by Schafer [2,3]. Moreover, one should mention that the inclusion of the DSM in the AS/NZS and NAS specifications for cold-formed steel design has been very recently approved - they already appear in the current (new) versions of these codes $[4,5]$. The method has been shown to provide an efficient general approach to estimate the ultimate strength of cold-formed steel columns and beams (i) exhibiting global (flexural, torsional or flexural-torsional), distortional or local-plate failure modes or (ii) failing in mechanisms that involve interaction between global and local-plate buckling modes. Indeed, the most recent DSM version stipulates the need to perform two independent safety checks, regardless of the member critical buckling mode nature: (i) one against a distortional failure and (ii) the other against a local-plate or a combined local-plate/global collapse. In the latter case, the DSM provides an efficient alternative to the more traditional and conservative "effective width method". However, as pointed out by Schafer [2, 3, 6, 7], further research is needed before the DSM approach can be successfully applied to members (i) under compression and bending $[8,9]$ or (ii) influenced by interaction phenomena involving distortional buckling modes [10-13]. Since it has been recently shown that the post-buckling and ultimate strength behaviours of various commonly used lipped channel cross-section shapes can be strongly affected by coupling between local-plate and distortional buckling modes [14-16], it would be obviously very convenient to have this mode interaction phenomenon also covered by the DSM.

The objective of this work is to contribute towards the extension of the domain of application of the available DSM, by making it able to estimate the ultimate strength of lipped channel columns affected by interaction involving local-plate and distortional buckling modes. In order to achieve this goal, one begins by presenting the main results of a shell finite element investigation (performed with the code ABAQUS [17]) concerning the elastic-plastic post-buckling behaviour (up to collapse) of lipped channel columns experiencing local-plate/distortional buckling mode interaction. Then, one reports an extensive parametric study involving the determination of the elastic-plastic failure loads of lipped channel 
columns with distinct cross-section dimensions, lengths and yield stresses, and containing critical-mode (distortional) small-amplitude initial geometrical imperfections - the columns were carefully selected, in order to exhibit strong local-plate/distortional interaction effects. All second-order elastic-plastic analyses were performed in the finite element code ABAQUS and discretising the columns into 4-node shell elements. These ultimate strength values then provide a "data bank" that makes it possible to propose and validate preliminary recommendations concerning the use of a DSM approach to estimate collapse loads of columns affected by local-plate/distortional mode interaction - as already mentioned, the results reported here deal with an ongoing investigation aimed at proposing (slight) modifications to the existing DSM equations, thus making them applicable to the design of lipped channel columns against this mode interaction phenomenon.

\section{LOCAL-PLATE/DISTORTIONAL BUCKLING MODE INTERACTION}

One reports here the main results of a recent investigation on the elastic-plastic post-buckling behaviour and ultimate strength of simply supported (plain) lipped-channel columns that are strongly affected by local-plate/distortional buckling mode interaction - the columns analysed (i) have the cross-section dimensions, length and elastic constants indicated in Figure. 1(a) and (ii) buckle elastically for $\sigma_{c r}=100.5$ $M P a$ in arbitrary combinations of (ii ${ }_{1}$ ) a 3 half-wave local-plate mode and (ii ${ }_{2}$ ) a single half-wave distortional mode, as illustrated in Figure. 1(b) [16]. The ultimate strengths were obtained through finite element analyses (FEA) carried out in the code ABAQUS [17] and adopting shell elements to discretise the columns. As far as the performance of these FEA is concerned, the following aspects deserve to be mentioned here $[14,18]$ :

(i) Discretisation. The column mid-surfaces were discretised into S4 finite elements (ABAQUS nomenclature: isoparametric 4-node shell elements with the shear stiffness yielded by a full integration rule), which were found to be the most adequate to carry out this task. One considered 20-30 elements along the cross-section mid-line (width of about $10 \mathrm{~mm}$ ) and previous convergence/accuracy studies showed that the finite element length-to-width ratio should be comprised between 1 and 2 .

(ii) Support Conditions. All columns have end sections locally/globally pinned and free to warp. Concerning the first aspect, these support conditions were modelled by imposing null transverse membrane and flexural displacements at all end section nodes - in order to preclude a spurious longitudinal rigid-body motion, the axial displacement was prevented at one mid-span cross-section node.

(iii) Loading. Compressive forces, statically equivalent to a uniform normal stress distribution, are applied at the nodes of the column end-sections. Since the reference value of the load parameter $p$ is $t \mathrm{~N} / \mathrm{mm}(t$ is the wall thickness), which corresponds to a $1 M P a$ uniform stress distribution, the value of $p$ yielded by ABAQUS is numerically equal to the average stress acting on the column (expressed in $M P a$ ).

(iv) Material Modelling. The column (carbon steel) material behaviour, deemed isotropic and homogeneous, was modelled through (iv 1 ) linear elastic (bifurcation analysis) and (ii) elastic/perfectly-plastic (post-buckling analysis) stress-strain laws. In the latter case, the well-known Prandtl-Reuss model ( $\mathrm{J}_{2}$-flow theory), which combines Von Mises's yield criterion with the associated flow rule, was adopted. These stress-strain laws are readily available in the ABAQUS material behaviour library and one just needs to provide the values of $E, v$ and $f_{y}$ - one considered $E=210 \mathrm{GPa}$ (Young's modulus), $v=0.3$ (Poisson's ratio) and five different yield stresses, which correspond to yield-to-critical stress ratios equal to $f_{y} / \sigma_{c r} \approx 1.2,2,3.5,5.5$ (in elastic columns, included here for the sake of completeness, one obviously considered $f_{y} / \sigma_{c r}=\infty$ ). 


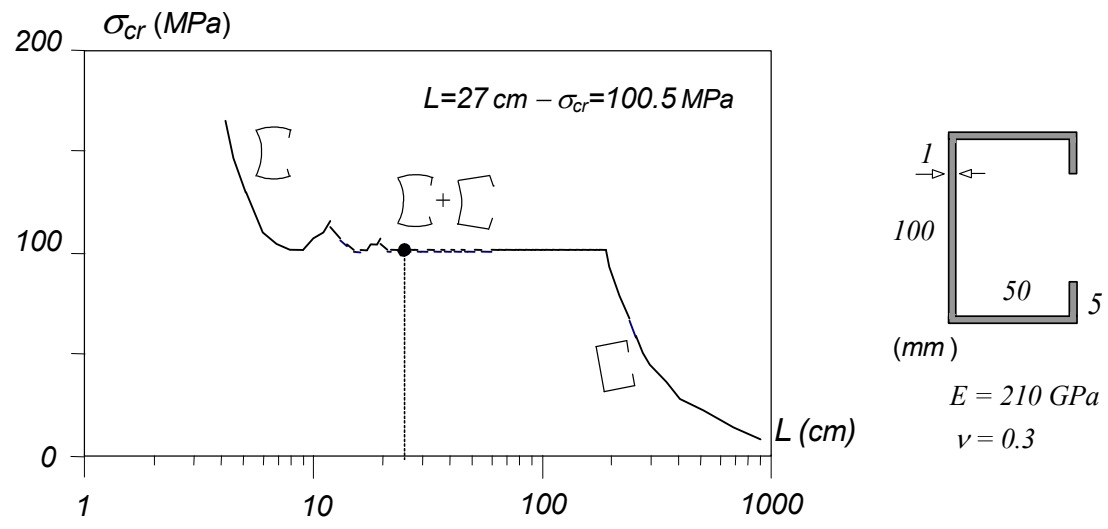

(a)

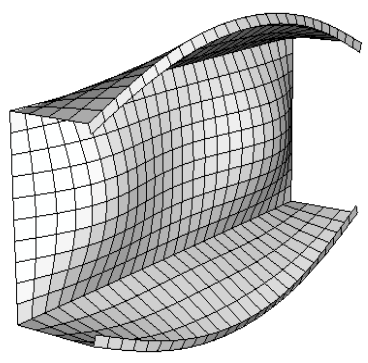

(b)

Figure 1. Buckling Results: (a) $\sigma_{c r} v s . L$ Curves (b) Critical "Combined” LP/D Mode Shape

\subsection{Initial Geometrical Imperfections}

The shape of the initial geometrical imperfections plays a crucial role in mode interaction investigations, since its choice may alter considerably the post-buckling behaviour and ultimate strength of the structural system under consideration. Indeed, the usual approach of including critical-mode imperfections ceases to be well defined, due to the presence of two "competing" buckling modes that may be combined arbitrarily - in this case, a three half -wave local-plate and a single half-wave distortional buckling modes. Thus, in order to obtain column equilibrium paths that (i) cover the whole imperfection shape range and (ii) can be compared in a meaningfully way, the following approach was adopted:

(i) To determine "pure" critical buckling modes with unit mid-span $\left(i_{1}\right)$ mid-web flexural displacement (local-plate $-w_{L P}=1$ ) and ( $\mathrm{i}_{2}$ ) flange-lip corner vertical displacement (distortional $\left.v_{D}=l\right)^{1}$ - these two modes were obtained through preliminary linear stability analyses, based on a finite element mesh identical to the one adopted in the post-buckling analyses. Then, a given "combined" (critical) imperfection is obtained as a linear combination of the pure modes, with coefficients $w_{L P .0}$ and $v_{D .0}$. Note that, in general, both buckling modes will contribute to $w_{0}$ and $v_{0}$, i.e., one has

$w_{0}=w_{D .0}+w_{L P .0} \quad v_{0}=v_{D .0}+v_{L P .0}$

where $w_{D .0}, w_{L P .0}, v_{D .0}$ and $v_{L P .0}$ quantify the aforementioned contributions.

(ii) All initial imperfections share the same overall magnitude, equal to $10 \%$ of the wall thickness $t$. In order to achieve this, one begins by normalising the pure modes in such a way that $w_{L P .0}=0.1$ $t$ and $v_{D .0}=0.1 t$ (in this particular case, $0.1 t=0.1 \mathrm{~mm}$ ). Then, one ensures the above combined amplitude by simply enforcing the condition

$\left(v_{D .0}\right)^{2}+\left(w_{L P .0}\right)^{2}=0.1^{2}$

\footnotetext{
${ }^{1}$ In order to be able to "separate" the local-plate and distortional modes, it was necessary to perform buckling FEA in columns with slightly altered wall thickness values.
} 
(iii) A better visualisation and "feel" of the initial imperfection shape can be obtained by looking at the $0.1 \mathrm{~mm}$ radius circle drawn in the $w_{L P .0} v_{D .0}$ plane and shown in Figure. 2(a): each "acceptable" imperfection shape lies on this circle and corresponds to an angle $\theta$, measured counter clockwise from the horizontal $\left(v_{D .0}\right)$ axis and defining the ratio $v_{D .0} / w_{L P .0}\left(v_{D .0}=0.1 \cos \theta\right.$ and $w_{L P .0}=0.1 \sin \theta$ ). Figure. 2(b) shows the FEM-based initial imperfections associated with $\theta=0,180^{\circ}$ and $\theta=90,270^{\circ}$ - pure distortional and pure local-plate. Finally, note that (iii ${ }_{1}$ ) $\theta=0^{\circ}$ and $\theta=180^{\circ}$ correspond to inward and outward flange-lip motions and (iii $\left.{ }_{2}\right) \theta=90^{\circ}$ and $\theta=270^{\circ}$ to outward and inward mid-span web bending.

(iv) In this work, initial imperfections associated with angles multiple of $15^{\circ}$ were considered - i.e., the 14 imperfection shapes defined by $\theta=0,30,45,60,90,120,150,180,210,240,270,300$, $315,330^{\circ}$.

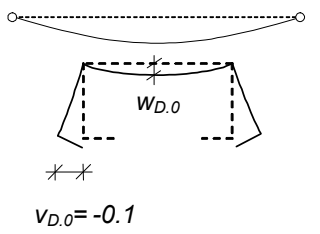

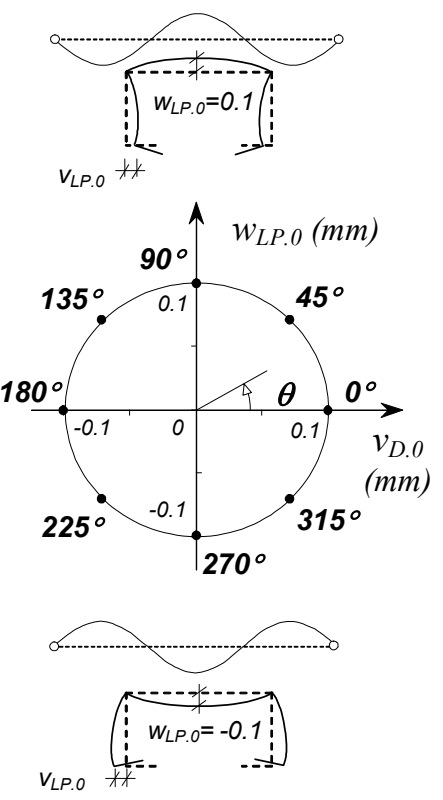

(a)

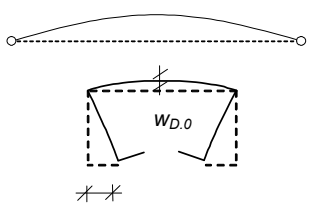

$v_{D .0}=0.1$

(b)

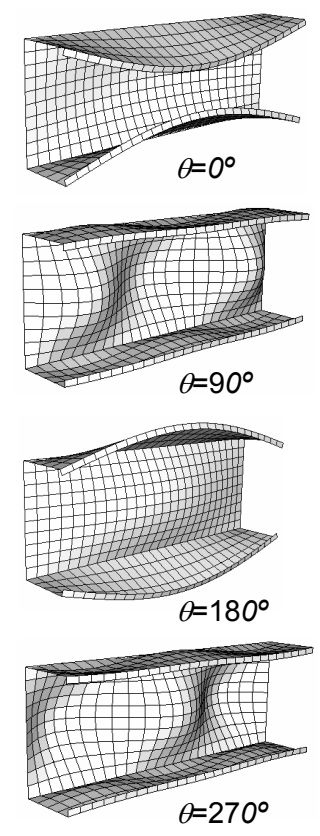

Figure 2. (a) Initial Geometrical Imperfection Representation in the $w_{L P .0}-v_{D .0}$ Plane and (b) Four FEM-Based Imperfection Shapes $\left(\theta=0,90,180,270^{\circ}\right)$

\subsection{Post-Buckling Equilibrium Paths}

One addresses now the influence of the local-plate/distortional mode interaction in the elastic-plastic post-buckling behaviour of lipped channel columns (i) containing the 14 initial imperfection shapes defined above (all with the same overall amplitude) and (ii) exhibiting the 5 yield-to-critical stress ratios $f_{y} / \sigma_{c r}$ given earlier (recall that one has $\sigma_{c r . L P}=\sigma_{c r . D}=100.5 \mathrm{MPa}$, which corresponds to $P_{c r}=21.1 \mathrm{kN}$ ). Figures. 3(a)-(b) show the upper portions $\left(P / P_{c r}>0.8\right)$ of the elastic and elastic-plastic equilibrium paths $P / P_{c r} v s . v / t$ describing the post-buckling behaviours of columns with (i) initial imperfections defined by $0 \leq \theta \leq 180^{\circ}$ (Figure. 3(a)) and $180 \leq \theta \leq 360^{\circ}$ (Figure. 3(b)), and (ii) yield-to-critical stress ratios $f_{y} / \sigma_{c r} \approx 2,3.5,5.5$. On the other hand, Figures. 4(a)-(b) show the upper portions $\left(P / P_{c r}>0.7\right)$ of similar equilibrium paths of columns with the lowest stress ratio $\left(f_{y} / \sigma_{c r} \approx 1.2\right)$. Finally, Figures. 5(a)-(b) provide information about the evolution of the plastic strains in the two columns defined by $\theta=0^{\circ}+f_{y} / \sigma_{c r} \approx 3.5$ and $\theta=90^{\circ}+f_{y} / \sigma_{c r} \approx 3.5-$ in each case, one presents 4 plastic strain diagrams, corresponding to different equilibrium states located along the post-buckling equilibrium path (their locations are indicated in Figure. 5(a)). It is worth noting that (i) the deformed configurations corresponding to the points 1 are amplified 10 times with respect to the remaining ones and that (ii) the points $\mathbf{4}$ always correspond to equilibrium states immediately after the column collapse - i.e., the associated deformed configurations provide information about the column failure modes. 


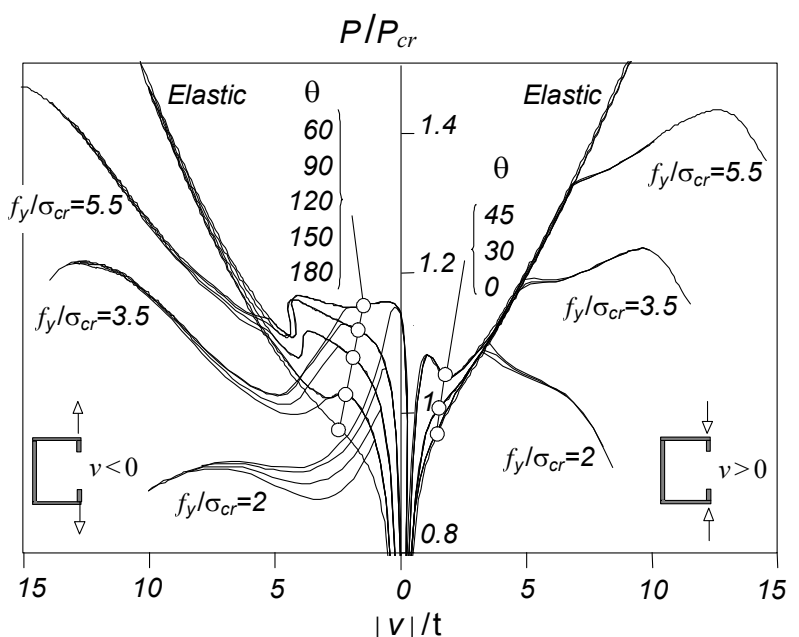

(a)

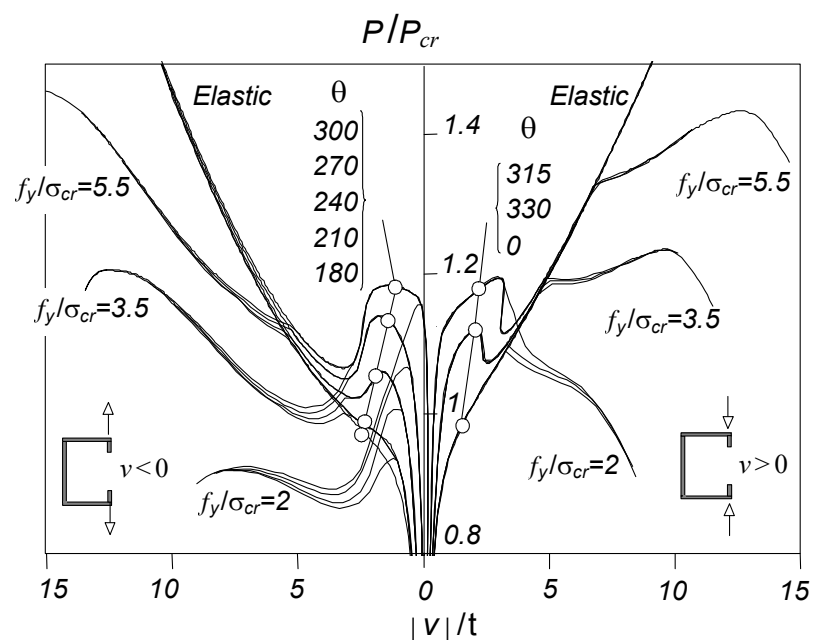

(b)

Figure 3. Column Elastic and Elastic-Plastic $\left(f_{y} / \sigma_{c r} \approx 2,3.5,5.5\right)$ Post-Buckling Equilibrium Paths $P / P_{c r} v s$. $v / t$ : (a) $0^{\circ} \leq \theta \leq 180^{\circ}$ and (b) $180^{\circ} \leq \theta \leq 360^{\circ}$

The observation of the post-buckling results presented in Figures. 3 to 5 prompts the following remarks:

(i) Even under local-plate/distortional (LP/D) mode interaction, there is a visible elastic post-buckling asymmetry concerning the columns with pure distortional imperfections: the $\theta=0^{\circ}$ (inward) column exhibits slightly higher post-buckling strengths than its $\theta=180^{\circ}$ (outward) counterpart. However, note that, regardless of the imperfection "sign", the column post-buckling strength is always a bit higher than in the absence of LP/D interaction, which stems from the progressive emergence of a (rather small) local-plate component, known to exhibit a much larger post-critical strength reserve - Figures 6(a)-(b) compare the evolutions of the $\theta=0^{\circ}$ and $\theta=180^{\circ}$ column web deformed configurations with an exact sinusoid shape - these comparisons clearly reveal the presence of the local-plate 3 half-wave sinusoidal component, thus confirming the occurrence of the buckling mode interaction [16].

(ii) All elastic equilibrium paths associated with predominantly local-plate imperfections (namely the ones concerning the $\theta=90^{\circ}$ and $\theta=270^{\circ}$ columns) exhibit a distinct "irregular" behaviour: regardless of the $w_{L P .0}$ sign, they $\left(\mathrm{ii}_{1}\right)$ are less "smooth" then the $\theta=0^{\circ}$ and $\theta=180^{\circ}$ column paths, which always evolve in a monotonic fashion, (ii 2 ) exhibit limit points, associated with "snap-through" phenomena ${ }^{2}$, and, for $P / P_{c r}>1.1$, (ii $\left.{ }_{3}\right)$ merge with either the $\theta=180^{\circ}$ column (majority of them) or $\theta=0^{\circ}$ column paths. This means that, even in the presence of pure 3 half-wave local-plate imperfections $\left(v_{D .0}=0\right)$, the column evolves towards a predominantly distortional single half-wave deformed configuration - this evolution often includes significant web bending reversal, which explains the occurrence of the limit points appearing in the (elastic) equilibrium paths displayed in Figures. 3(a)-(b).

(iii) Generally speaking, the elastic-plastic equilibrium paths of the various columns also merge with the ones corresponding to $\theta=0^{\circ}$ or $\theta=180^{\circ}$. Depending on the $f_{y} / \sigma_{c r}$ value, this merging may occur after or before the column has reached its ultimate strength - see Figures. 3(a)-(b). However, merging never occurs for $f_{y} / \sigma_{c r} \approx 1.2$ - an explanation for this fact is provided below, in item (vi).

\footnotetext{
2 The "snap-through" becomes more "abrupt" as the amplitude of the initial imperfection local-plate component grows. When the imperfections are pure or "almost pure", one even observes a minor "snap-back" phenomenon (e.g., the $\theta=90^{\circ}$ column).
} 
(iv) The onset of yielding always takes place inside the load interval $0.8<P / P_{c r}<1.3$ (obviously, the exact load value depends on the yield-to-critical stress ratio and initial imperfection shape) and defines the point of separation between the elastic and elastic-plastic equilibrium paths. For a given $f_{y} / \sigma_{c r}$ value, this separation takes place for higher load levels in columns with pure local-plate imperfections $\left(\theta=90^{\circ}\right.$ or $\left.\theta=270^{\circ}\right)$ than in columns with pure distortional ones $\left(\theta=0^{\circ}\right.$ or $\left.\theta=180^{\circ}\right)-$ the difference may reach about $20 \%$ (e.g., $\theta=180^{\circ} v s . \theta=270^{\circ}$, for $\left.f_{y} / \sigma_{c r} \approx 2\right)$.

(v) For $f_{y} / \sigma_{c r} \geq 2$, plasticity appears first at the free ends of the mid-span cross-section section lips, as shown in Figures. 5( $\left.\mathrm{b}_{1}\right)-\left(\mathrm{b}_{2}\right)$.

(vi) For $f_{y} / \sigma_{c r} \approx 1.2$, yielding starts while the column is still subjected to a fairly uniform stress distribution, leading to a very "sudden" collapse - a large portion of the column yields at practically the same time. In this case, the shape of the initial imperfection governs the location of zone where yielding begins.

(vii) For $f_{y} / \sigma_{c r} \geq 3.5$, collapse only occurs after the full yielding of the column mid-span zones located around the web-flange corners, as shown in the right side of Figures. $5\left(b_{1}\right)-\left(b_{2}\right)$. However, one should point out that the collapse mechanism is different in columns with outward and inward flange-lip motions. In the former, one observes the formation of a "three hinge flange mechanism" - see the right side of Figure. $5\left(\mathrm{~b}_{2}\right)$. In the latter, the plastic deformation is restricted to the close vicinity of the mid-span cross-section - see the right side of Figure. 5( $\left.b_{1}\right)$.

(viii) For $f_{y} / \sigma_{c r} \geq 3.5$, the onset of yielding does not precipitate failure, even when associated with a "snap-through" phenomenon (e.g., $f_{y} / \sigma_{c r} \approx 3.5$ and any imperfection shape with a local-plate component) - the column still exhibits a certain amount of post-bucking strength reserve, which is more substantial for $f_{y} / \sigma_{c r} \approx 5.5$ and outward flange-lip motion - see Figure. 3(a). It is still worth noting that failure occurs after the various equilibrium paths have already merged together, which means that the initial imperfection shape has little influence on the column load-carrying capacity and failure mechanism.

(ix) The outward pure distortional initial imperfection is the most detrimental one, as it leads to the lowest column load-carrying capacities. This feature has far-reaching implications in the design of cold-formed steel columns affected by local-plate/distortional mode interaction - see the next subsection.

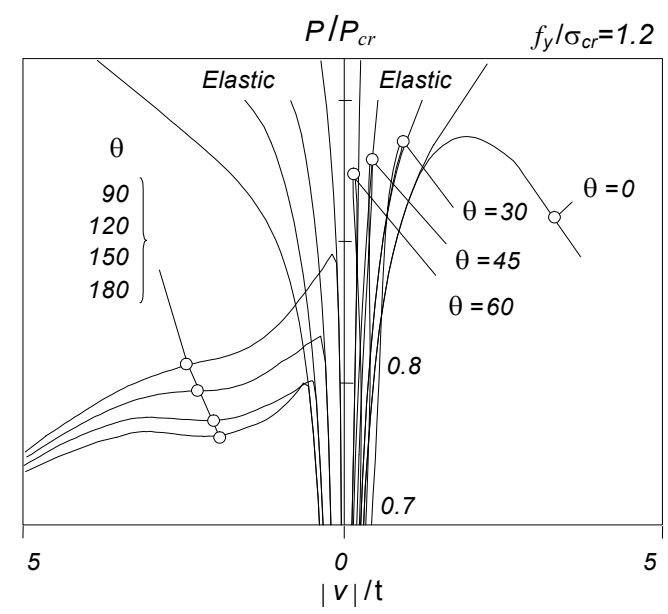

(a)

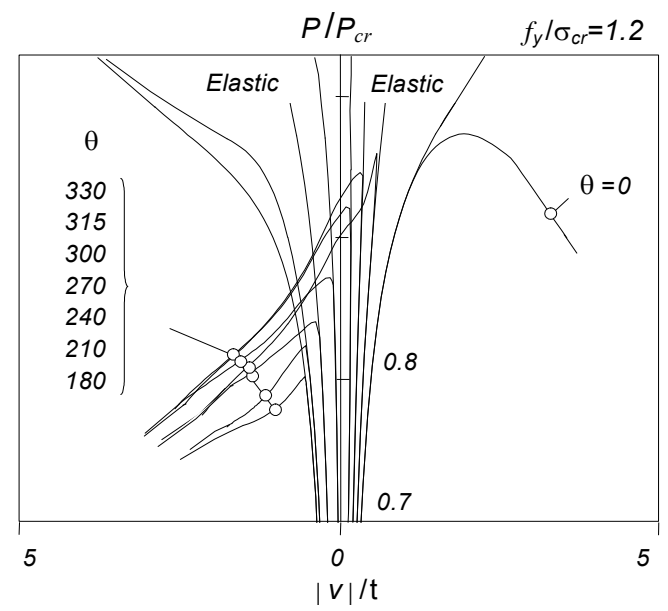

(b)

Figure 4. Column Elastic and Elastic-Plastic $\left(f_{y} / \sigma_{c r} \approx 1.2\right)$ Post-Buckling Equilibrium Paths $P / P_{c r} v s$. v/t: (a) $0^{\circ} \leq \theta \leq 180^{\circ}$ and (b) $180^{\circ} \leq \theta \leq 360^{\circ}$ 


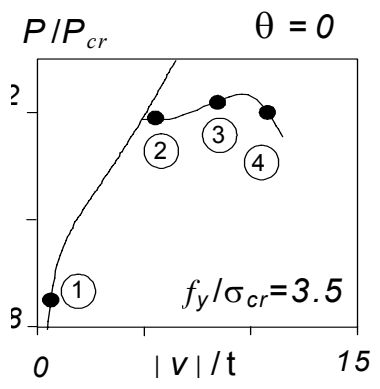

$\left(\mathrm{a}_{1}\right)$

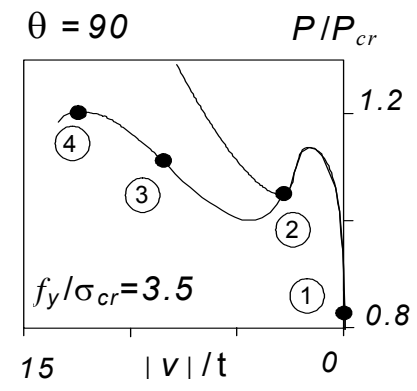

$\left(a_{2}\right)$
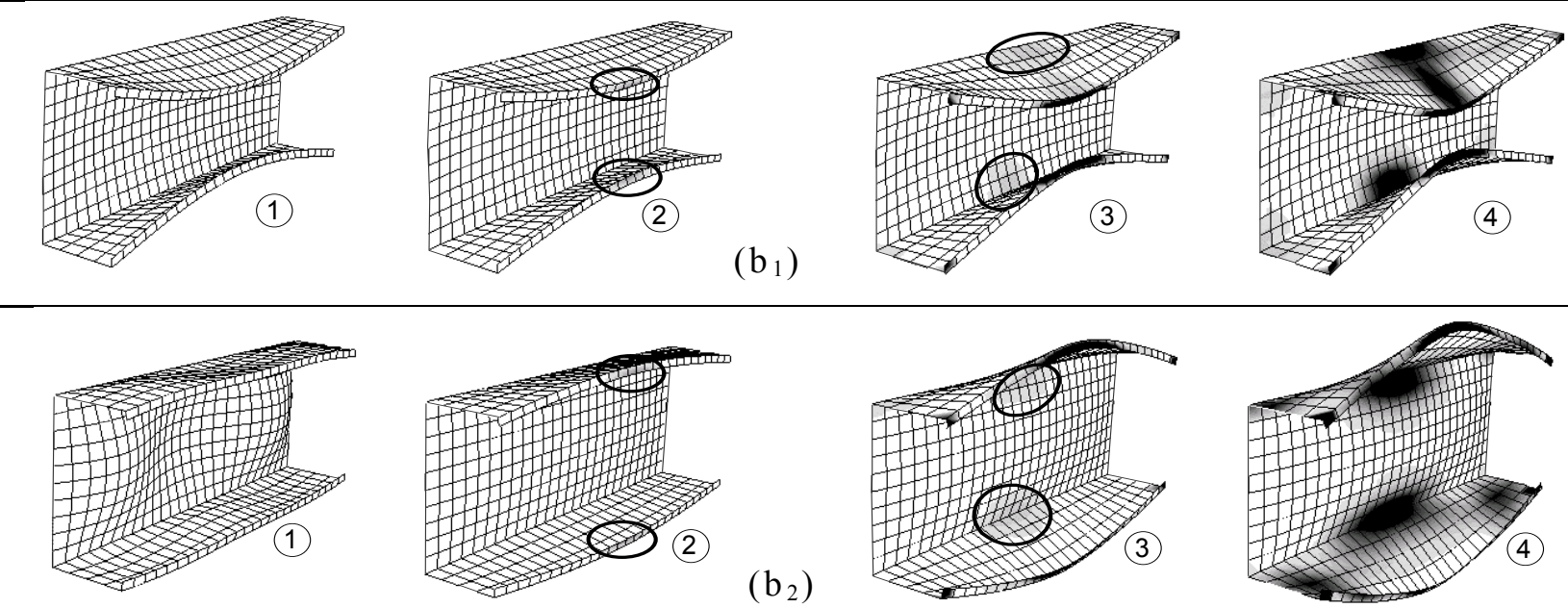

$\left(b_{1}\right)$

$\left(b_{2}\right)$
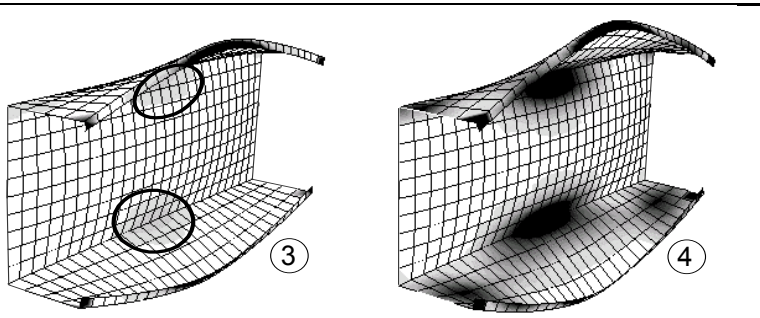

Figure 5. (a) Equilibrium Points on $P / P_{c r} v s . v / t$ Post-Buckling Paths and (b) Associated Plastic Strain Diagrams and Failure Modes for Columns Defined by:

(1) $\theta=0^{\circ}+f_{y} / \sigma_{c r} \approx 3.5$ and (2) $\theta=90^{\circ}+f_{y} / \sigma_{c r} \approx 3.5$

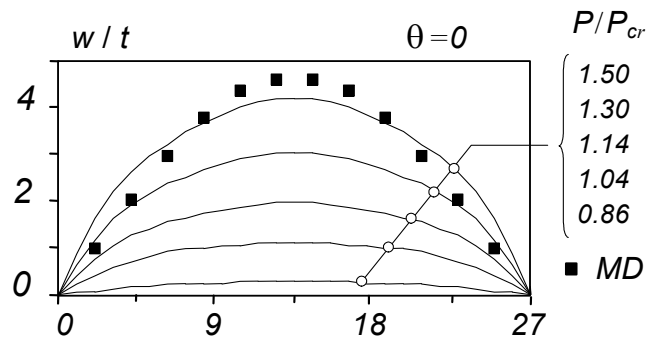

(a)

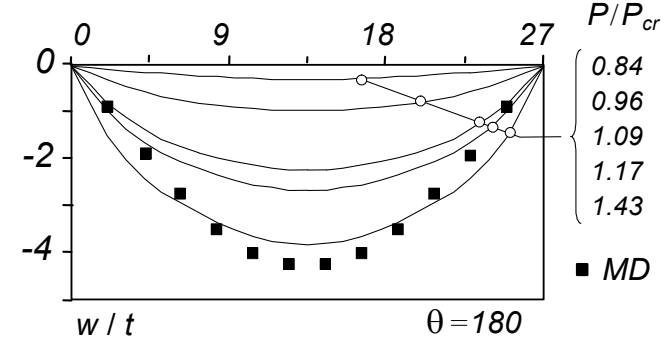

(b)

Figure 6. Web Deformed Configuration Evolution for the (a) $\theta=0^{\circ}$ and (b) $\theta=180^{\circ}$ Columns

\section{DIRECT STRENGTH METHOD}

Next, one presents the results of an investigation aimed at developing and assessing the performance of an approach based on the Direct Strength Method (DSM) and intended to estimate the ultimate strength of lipped channel columns affected by LP/D mode interaction $[12,13]$. In order to achieve this goal in a proper fashion, it is indispensable to possess a significant amount of reliable experimental and/or numerical ultimate strength values concerning columns with close (almost coincident) local-plate and distortional critical buckling stresses. Therefore, it was decided to carry out an extensive parametric study, destined to acquire a fairly large data bank of column ultimate strengths on which to base the assessment and/or improvement of the current DSM design methodology - these ultimate strengths were obtained through 
second-order elastic-plastic shell finite element analyses performed in the code ABAQUS [17], as briefly described earlier.

\subsection{Current DSM Design Approach}

When compared with the traditional "effective width approach", the DSM exhibits three major innovative features, all stemming from the fact that the cross-section is now viewed as a whole: (i) wall-restraint effects are automatically taken into account, (ii) no effective width calculations are needed and (iii) it is possible to provide strength estimates for members failing in distortional modes. Moreover, the DSM provides a rational and systematic framework for the design of thin-walled members with arbitrary cross-section shapes, loadings or failure modes - of course, a given application needs proper calibration and validation (i.e., comparison with a fair number of experimental and/or numerical results). Finally, note that both the DSM and effective width approaches share the same basic assumption: the member ultimate strength can be accurately predicted solely on the basis of its elastic buckling and yield stresses.

The available DSM applications adopt "Winter-type" design curves, which have been calibrated against a large number of experimental and/or numerical results [19]. It was shown that, whenever a given column fails in pure local-plate or distortional modes, it is possible to obtain safe and accurate ultimate strength estimates on the basis of the elastic buckling and yield stress values. Thus, the DSM prescribes that the column nominal strengths against local-plate and distortional failure $\left(P_{N L}\right.$ and $\left.P_{N D}\right)$ are given by the expressions [2]

$$
\begin{aligned}
& \left\{\begin{array}{l}
P_{N L}=P_{Y} \quad \text { if } \quad \lambda_{L} \leq 0.776 \\
P_{N L}=P_{Y}\left(\frac{P_{C R L}}{P_{Y}}\right)^{0.4}\left[1-0.15\left(\frac{P_{C R L}}{P_{Y}}\right)^{0.4}\right] \quad \text { if } \quad \lambda_{L}>0.776
\end{array}\right. \\
& \left\{\begin{array}{l}
P_{N D}=P_{Y} \quad \text { if } \quad \lambda_{D} \leq 0.561 \\
P_{N D}=P_{Y}\left(\frac{P_{C R D}}{P_{Y}}\right)^{0.6}\left[1-0.25\left(\frac{P_{C R D}}{P_{Y}}\right)^{0.6}\right] \quad \text { if } \quad \lambda_{D}>0.561
\end{array}\right.
\end{aligned}
$$

where (i) $\lambda_{L}=\left(P_{Y} / P_{C R L}\right)^{0.5}$ and $\lambda_{D}=\left(P_{Y} / P_{C R D}\right)^{0.5}$, (ii) $P_{Y}$ is the squash load and (iii) $P_{C R L}$ and $P_{C R D}$ are the local-plate and distortional critical buckling loads. In order to capture the local-plate/global or distortional/global interaction, the DSM approach proposes the replacement of $P_{Y}$ by $P_{N E}$ in Eq. 3 or Eq. 4, where $P_{N E}$ is the column buckling strength associated with global (Euler) failure. At this point, it is worth noting that an accurate prediction of the column distortional failure load has considerable practical relevance, since (i) the distortional post-critical strength reserve is considerably lower and more imperfection-sensitive than its local-plate counterpart and (ii) there exists clear (numerical) evidence that the collapse of columns buckling in local-plate modes is often associated with a distortional failure mechanism [14].

\subsection{DSM for Local-Plate/Distortional Interaction}

Following a strategy similar to the one used to develop safety-checking rules that account for local-plate/global effects, it is possible to propose expressions to estimate the ultimate strength of columns experiencing local-plate/distortional interaction. This was first achieved by Schafer [20, 21], who proposed two distinct approaches: (i) replacing $P_{Y}$ by $P_{N D}$ in Eq. 3 (NLD approach - schematically depicted in the flowchart shown in Figure. 7(a)) or (ii) replacing $P_{Y}$ by $P_{N L}$ in Eq. 4 (NDL approach - see Figure. 7(b)), where $P_{N D}$ and $P_{N L}$ are the distortional and local-plate buckling strengths also given by Eqs. 3 and 4. Yang and Hancock [10] recently adopted the NLD approach to investigate the LP/D 
interaction in lipped channel columns with "v-shape" web and flange intermediate stiffeners. After comparing the ultimate strength estimates provided by the NLD approach with the results of a series of experimental tests performed in Sydney, which provided evidence of adverse local-plate/distortional interaction, these authors concluded that (i) the above estimates were always safe and reasonably accurate (differences within the 10-20\% range) and also that (ii) further investigation is required on the design of columns with nearly coincident local-plate and distortional buckling stresses. Finally, note that the use of Eqs. 3 and 4 requires the knowledge of accurate local-plate and distortional buckling loads $\left(P_{C R L}, P_{C R D}\right)$, which can be obtained through shell finite element analyses, finite strip analyses or Generalised Beam Theory (GBT) analyses.

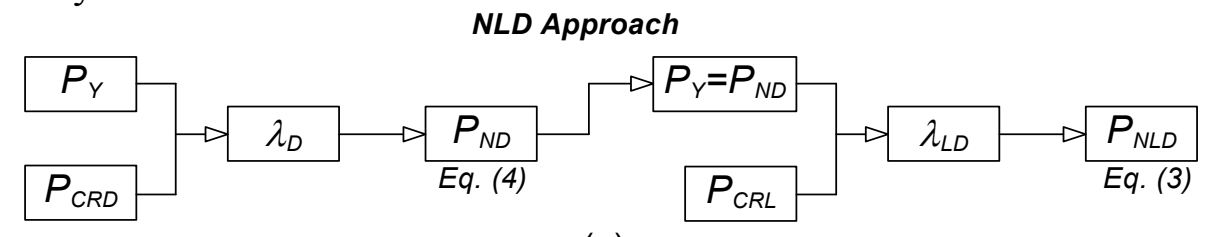

(a)

NDL Approach

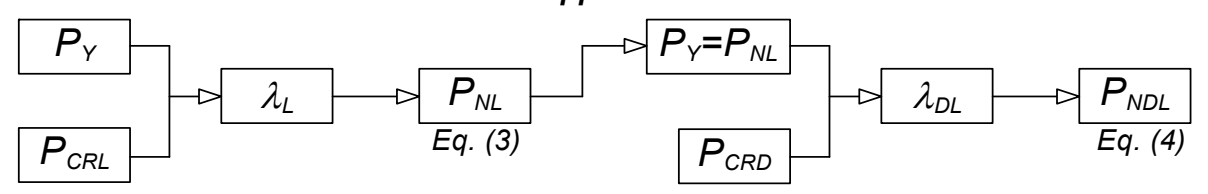

(b)

Figure 7. Flowcharts Concerning the Determination of the Nominal Strength of Columns Experiencing LP/D Interaction Effects: (a) $P_{N L D}$ and (b) $P_{N D L}$ Approaches

\section{PARAMETRIC STUDY: SCOPE AND NUMERICAL RESULTS}

In order to be able to carry out a fairly large parametric study involving the ultimate strength of lipped channel columns affected by local-plate/distortional interaction, their geometries had to be carefully selected: it was necessary to find sets of cross-section dimensions and length values making it possible to "control" the closeness between the column local-plate and distortional critical buckling stresses ( $\sigma_{C R L}$ and $\left.\sigma_{C R D}\right)$ or loads $\left(P_{C R L}\right.$ and $\left.P_{C R D}\right)$. This goal was achieved by adopting the following strategy:

(i) Initially, a trial-and-error approach was employed to find six "basic cross-section shapes", displaying commonly used dimensions and ensuring the coincidence between $\sigma_{C R L}$ and $\sigma_{C R D}$. This search led to the three slender $\left(1.4 \leq \lambda_{D} \leq 2.6\right)$ and three stocky $\left(0.6 \leq \lambda_{D} \leq 1.4\right)$ cross-sections exhibiting the following dimensions (web width $b_{w}$, flange width $b_{f}$, stiffener/lip width $b_{s}$ and wall thickness $t$ )

(i.1) Slender cross-sections: $\left(i_{1}\right) b_{w}=100, b_{f}=50, b_{s}=5, t=1.0 m m$ (Slender Column $1-$ SLC1), $\left(\mathrm{i}_{2}\right) b_{w}=120, b_{f}=80, b_{s}=10, t=1.3 \mathrm{~mm}(\mathrm{SLC} 2)$ and $\left(\mathrm{i}_{3}\right) b_{w}=95, b_{f}=80, b_{s}=10, t=0.95 \mathrm{~mm}$ (SLC3).

(i.2) Stocky cross-sections: (i $\left.\mathrm{i}_{1}\right) b_{w}=180, b_{f}=100, b_{s}=20, t=3.4 m m$ (Stocky Column $1-$ STC1), (i $\left.i_{2}\right)$ $b_{w}=110, b_{f}=78, b_{s}=30, t=2.8 \mathrm{~mm}(\mathrm{STC} 2)$ and $\left(\mathrm{i}_{3}\right) b_{w}=100, b_{f}=100, b_{s}=26, t=2.0 \mathrm{~mm}$ (STC3).

One should mention that all the above six column cross-section dimensions satisfy the requirements that have been adopted in the existing DSM approach - i.e., they are "pre-qualified columns".

(ii) Subsequently, the closeness between $\sigma_{C R L}$ and $\sigma_{C R D}$ was slightly altered, by just changing a single basic cross-section dimension: either the flange width $b_{f}$, the web width $b_{w}$ or the stiffener width $b_{s}$. This procedure led to the identification of various columns with (ii $i_{1}$ ) cross-section dimensions generated from the six basic shapes and (ii 2 ) very close (but not necessarily coincident) $\sigma_{C R L}$ and $\sigma_{C R D}$ values - the alterations were made in such a way that one has always $0.90 \leq \sigma_{C R L} / \sigma_{C R D} \leq 1.10$ (i.e., the critical stresses are never more than $10 \%$ apart). 
Concerning the column lengths considered, they always correspond to single distortional half-waves associated with the buckling stresses $\sigma_{C R D}$ and were determined by means of finite strip analyses. As for the column steel material behaviour, it is characterised by $E=210 \mathrm{GPa}$ (Young's modulus), $v=0.3$ (Poisson's ratio) and $f_{y}=250-350-550 \mathrm{MPa}$ (three yield stress values are considered in this work, all of them also meeting the DSM limit stress requirements for "pre-qualified columns"). Finally, it is worth (i) mentioning that no residual stresses have been taken into account (it has been shown that have very little impact on the column ultimate strength - e.g., $[22,23]$ ) and (ii) addressing the criterion adopted to select the initial geometrical imperfections included in the non-linear analyses that provide the column ultimate strengths:

(i) Regardless of their critical stress ratios $\sigma_{C R L} / \sigma_{C R D}$, all the columns analysed contained initial geometrical imperfections with a single-wave distortional buckling mode shape, having an amplitude (mid-span flange-lip corner displacement) equal to $10 \%$ of the wall thickness $t$ and involving outward motions of the flange-lip assemblies - previous studies involving lipped channel columns with $\sigma_{C R L}=\sigma_{C R D}$ showed that this imperfection shape is the most detrimental one, in the sense that it corresponds to the lowest column post-buckling strength and collapse load $[15,16]$.

(ii) The slender columns with $\sigma_{C R L} / \sigma_{C R D}<1.0$ (i.e., with critical local-plate buckling modes exhibiting several half-waves) were also analysed in the presence of critical-mode initial geometrical imperfections, again with amplitude $0.1 t$ - it now corresponds to the mid-web flexural displacement at mid-span.

(iii) All initial geometrical imperfections defined earlier (buckling mode shapes with amplitude $0.1 t$ ) are included in the analyses through a specific ABAQUS command. In the columns buckling in local-plate modes $\left(\sigma_{C R L}<\sigma_{C R D}\right)$, the single-wave distortional imperfection is, effectively, the column higher-order buckling mode most resembling it, which means that it is not possible to guarantee the complete "purity" of the distortional shape - in other words, a small participation of a multiple half-wave local-plate mode is virtually undetectable (but with only a very minute affect the column ultimate strength).

A total of 66 slender and 45 stocky columns were analysed, corresponding to all possible combinations of 16 (15) different cross-section shapes and 3 yield stress values. All cross-section dimensions $\left(b_{w}, b_{f}, b_{s}, t\right)$, lengths $(L)$, critical stresses $\left(\sigma_{C R L}, \sigma_{C R D}\right)$, yield stresses $\left(f_{y}\right)$ and initial imperfection shapes $(D, L P)$ considered in this work are given in Tables 1-2 (slender columns) and 3-4 (stocky columns), presented further ahead.

The numerical results displayed in Tables 1 to 4 consist of column average stresses at collapse $\left(\sigma_{U}=P_{U} / A\right)$ and the nature of the corresponding failure mechanisms. In order to convey the meaning of these results, they are illustrated in Figure. 8(a), which shows the post-buckling equilibrium paths $\left(\sigma \sigma_{C R} v s . v / t\right)$ concerning columns with (i) $\sigma_{C R L}=\sigma_{C R D}\left(\equiv \sigma_{C R}\right)$, (ii) identical outward distortional imperfections and (iii) four different yield stresses $\left(f_{y} / \sigma_{C R} \approx 1.2,2.0,3.5,5.5\right)$. It is worth noting that the onset of yielding, which always takes place in the stiffener free ends (see Figure. $8\left(\mathrm{~b}_{1}\right)$ ), occurs at the equilibrium points $\mathbf{A}$ and may or may not trigger the column failure - it depends on the particular $f_{y} / \sigma_{C R}$ value. Indeed, for large enough $f_{y}$ $/ \sigma_{C R}$ values, failure occurs at a limit point $\mathbf{B}$, following (i) a "snap-through" phenomenon and (ii) the yielding of the column central regions located around the web-flange corners (see Figure. 8( $\left.b_{2}\right)$ ) Figure. 8(c) shows the corresponding (predominantly distortional) failure mechanism. 


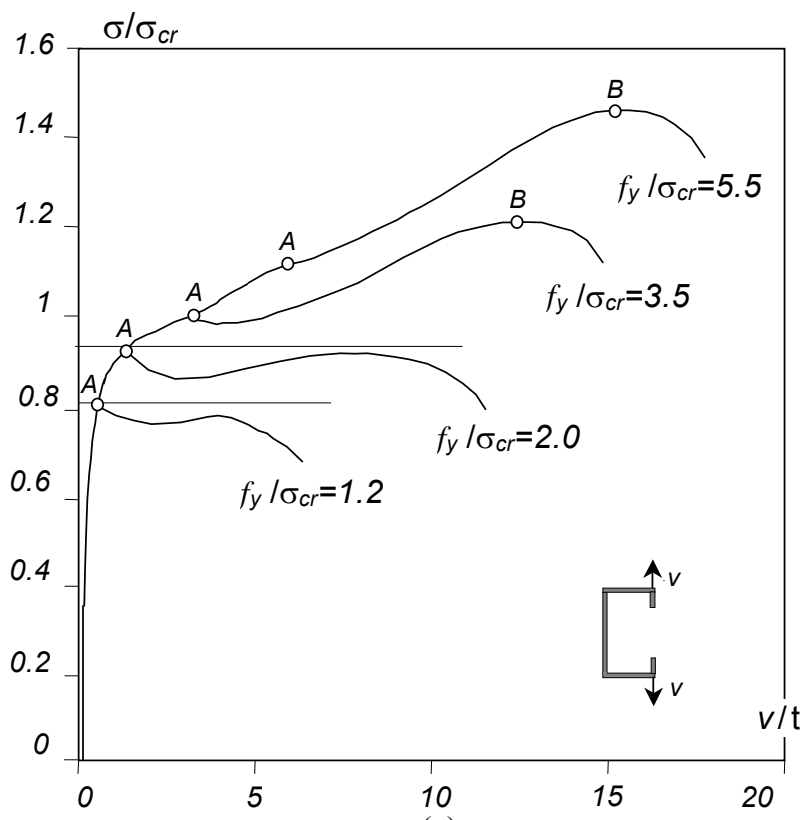

(a)

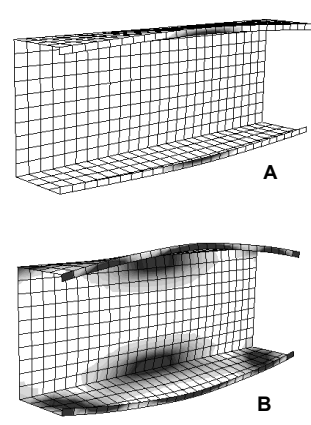

(b)

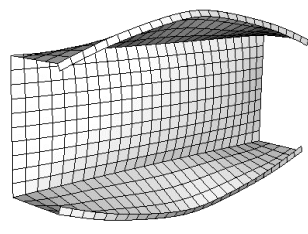

(c)

Figure 8. Column (a) Post-Buckling Equilibrium Paths,

(b) Plastic Strain Distributions and (c) Failure Mechanism

Table 1(a). Comparison Between the "Exact" and DSM $\left(\sigma_{N L D}\right)$ Ultimate Strength Estimates (SLC1)

\begin{tabular}{|c|c|c|c|c|c|c|c|c|c|c|c|c|c|}
\hline & & & & & \multicolumn{4}{|c|}{ FEA } & \multicolumn{4}{|c|}{ DSM } & \multirow[b]{2}{*}{$\sigma_{N L D} / \sigma_{U}$} \\
\hline & $b_{f}$ & $L$ & Imp. & $f_{y}$ & $\sigma_{\mathrm{L}}$ & $\sigma_{D}$ & $\sigma_{u}$ & Fail. & $\lambda_{D}$ & $\sigma_{\mathrm{ND}}$ & $\lambda_{\mathrm{LD}}$ & $\sigma_{N L D}$ & \\
\hline \multirow{21}{*}{ 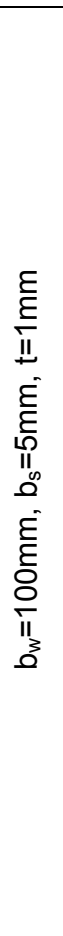 } & \multirow{3}{*}{55} & \multirow{3}{*}{300} & \multirow{3}{*}{ D } & 250 & \multirow{3}{*}{101} & \multirow{3}{*}{91} & 94 & $B$ & 1.66 & 117 & 1.08 & 95 & 1.01 \\
\hline & & & & 350 & & & 110 & B & 1.97 & 138 & 1.17 & 106 & 0.96 \\
\hline & & & & 550 & & & 131 & A & 2.46 & 171 & 1.30 & 121 & 0.93 \\
\hline & \multirow{3}{*}{52.5} & \multirow{3}{*}{280} & \multirow{3}{*}{ D } & 250 & \multirow{3}{*}{101} & \multirow{3}{*}{96} & 97 & $B$ & 1.61 & 121 & 1.09 & 97 & 1.00 \\
\hline & & & & 350 & & & 114 & $B$ & 1.91 & 143 & 1.19 & 108 & 0.95 \\
\hline & & & & 550 & & & 137 & A & 2.39 & 176 & 1.32 & 124 & 0.91 \\
\hline & \multirow{3}{*}{50} & \multirow{3}{*}{270} & \multirow{3}{*}{ D } & 250 & \multirow{3}{*}{102} & \multirow{3}{*}{102} & 102 & B & 1.57 & 125 & 1.11 & 99 & 0.97 \\
\hline & & & & 350 & & & 120 & $B$ & 1.85 & 147 & 1.20 & 110 & 0.92 \\
\hline & & & & 550 & & & 147 & A & 2.32 & 182 & 1.34 & 127 & 0.86 \\
\hline & \multirow{3}{*}{47.5} & \multirow{3}{*}{260} & \multirow{3}{*}{ D } & 250 & \multirow{3}{*}{102} & \multirow{3}{*}{108} & 107 & $B$ & 1.52 & 128 & 1.12 & 101 & 0.94 \\
\hline & & & & 350 & & & 127 & B & 1.80 & 151 & 1.22 & 113 & 0.89 \\
\hline & & & & 550 & & & 156 & $\mathrm{~A}$ & 2.26 & 187 & 1.35 & 130 & 0.83 \\
\hline & \multirow{3}{*}{45} & \multirow{3}{*}{260} & \multirow{3}{*}{ D } & 250 & \multirow{3}{*}{103} & \multirow{3}{*}{113} & 115 & $B$ & 1.48 & 131 & 1.13 & 103 & 0.90 \\
\hline & & & & 350 & & & 136 & B & 1.76 & 155 & 1.23 & 115 & 0.85 \\
\hline & & & & 550 & & & 168 & $A$ & 2.20 & 193 & 1.37 & 132 & 0.79 \\
\hline & \multirow{3}{*}{47.5} & & & 250 & & & 118 & $A$ & 1.52 & 128 & 1.12 & 101 & 0.86 \\
\hline & & 260 & LP & 350 & 102 & 108 & 127 & B & 1.80 & 151 & 1.22 & 113 & 0.89 \\
\hline & & & & 550 & & & 157 & $B$ & 2.26 & 187 & 1.35 & 130 & 0.83 \\
\hline & & & & 250 & & & 128 & $\mathrm{~A}$ & 1.48 & 131 & 1.13 & 103 & 0.80 \\
\hline & 45 & 260 & LP & 350 & 103 & 113 & 142 & B & 1.76 & 155 & 1.23 & 115 & 0.81 \\
\hline & & & & 550 & & & 168 & $B$ & 2.20 & 193 & 1.37 & 132 & 0.79 \\
\hline
\end{tabular}


Table 1(b). Comparison Between the "Exact" and DSM $\left(\sigma_{N L D}\right)$ Ultimate Strength Estimates (SLC2)

\begin{tabular}{|c|c|c|c|c|c|c|c|c|c|c|c|c|c|}
\hline & & & & & \multicolumn{4}{|c|}{ FEA } & \multicolumn{4}{|c|}{ DSM } & \multirow[b]{2}{*}{$\sigma_{N L D} / \sigma_{U}$} \\
\hline & $b_{w}$ & L & Imp. & $f_{y}$ & $\sigma_{\mathrm{L}}$ & $\sigma_{D}$ & $\sigma_{u}$ & Fail. & $\lambda_{D}$ & $\sigma_{\mathrm{ND}}$ & $\lambda_{\mathrm{LD}}$ & $\sigma_{\mathrm{NLD}}$ & \\
\hline \multirow{24}{*}{$\begin{array}{l}\text { है } \\
\text { ֻे } \\
\prod_{+}\end{array}$} & \multirow{3}{*}{130} & \multirow{3}{*}{550} & \multirow{3}{*}{ D } & 250 & \multirow{3}{*}{100} & \multirow{3}{*}{110} & 105 & $A$ & 1.51 & 129 & 1.14 & 101 & 0.96 \\
\hline & & & & 350 & & & 107 & B & 1.78 & 153 & 1.24 & 113 & 1.05 \\
\hline & & & & 550 & & & 123 & B & 2.24 & 189 & 1.38 & 130 & 1.05 \\
\hline & \multirow{3}{*}{125} & \multirow{3}{*}{550} & \multirow{3}{*}{ D } & 250 & \multirow{3}{*}{107} & \multirow{3}{*}{113} & 107 & $A$ & 1.49 & 131 & 1.11 & 104 & 0.97 \\
\hline & & & & 350 & & & 109 & A & 1.76 & 155 & 1.20 & 116 & 1.07 \\
\hline & & & & 550 & & & 123 & B & 2.21 & 192 & 1.34 & 134 & 1.09 \\
\hline & \multirow{3}{*}{120} & \multirow{3}{*}{550} & \multirow{3}{*}{ D } & 250 & \multirow{3}{*}{115} & \multirow{3}{*}{115} & 109 & A & 1.47 & 133 & 1.07 & 108 & 0.99 \\
\hline & & & & 350 & & & 111 & A & 1.74 & 157 & 1.17 & 120 & 1.08 \\
\hline & & & & 550 & & & 124 & B & 2.18 & 194 & 1.30 & 139 & 1.12 \\
\hline & \multirow{3}{*}{115} & \multirow{3}{*}{550} & \multirow{3}{*}{ D } & 250 & \multirow{3}{*}{124} & \multirow{3}{*}{118} & 112 & A & 1.45 & 134 & 1.04 & 111 & 0.99 \\
\hline & & & & 350 & & & 114 & A & 1.72 & 159 & 1.13 & 124 & 1.09 \\
\hline & & & & 550 & & & 122 & B & 2.16 & 197 & 1.26 & 143 & 1.18 \\
\hline & \multirow{3}{*}{110} & \multirow{3}{*}{550} & \multirow{3}{*}{ D } & 250 & \multirow{3}{*}{135} & \multirow{3}{*}{121} & 114 & $A$ & 1.44 & 136 & 1.00 & 115 & 1.01 \\
\hline & & & & 350 & & & 116 & $A$ & 1.70 & 161 & 1.09 & 129 & 1.11 \\
\hline & & & & 550 & & & 121 & A & 2.13 & 199 & 1.22 & 149 & 1.23 \\
\hline & & & & 250 & & & 119 & A & 1.40 & 139 & 0.94 & 123 & 1.03 \\
\hline & 100 & 550 & D & 350 & 157 & 127 & 122 & A & 1.66 & 164 & 1.02 & 138 & 1.13 \\
\hline & & & & 550 & & & 126 & A & 2.08 & 204 & 1.14 & 159 & 1.26 \\
\hline & & & & 250 & & & 119 & A & 1.49 & 131 & 1.11 & 104 & 0.88 \\
\hline & 125 & 550 & LP & 350 & 107 & 113 & 120 & $A$ & 1.76 & 155 & 1.20 & 116 & 0.97 \\
\hline & & & & 550 & & & 122 & $B$ & 2.21 & 192 & 1.34 & 134 & 1.10 \\
\hline & & & & 250 & & & 120 & A & 1.51 & 129 & 1.14 & 101 & 0.84 \\
\hline & 130 & 550 & LP & 350 & 100 & 110 & 121 & A & 1.78 & 153 & 1.24 & 113 & 0.93 \\
\hline & & & & 550 & & & 123 & $B$ & 2.24 & 189 & 1.38 & 130 & 1.05 \\
\hline
\end{tabular}

Table 1(c). Comparison Between the "Exact" and DSM $\left(\sigma_{N L D}\right)$ Ultimate Strength Estimates (SLC3)

\begin{tabular}{|c|c|c|c|c|c|c|c|c|c|c|c|c|c|}
\hline & & & & & \multicolumn{4}{|c|}{ FEA } & \multicolumn{4}{|c|}{ DSM } & \multirow[b]{2}{*}{$\sigma_{N L D} / \sigma_{U}$} \\
\hline & $b_{s}$ & $\mathrm{~L}$ & Imp & $f_{y}$ & $\sigma_{\mathrm{L}}$ & $\sigma_{D}$ & $\sigma_{U}$ & Fail. & $\lambda_{D}$ & $\sigma_{\mathrm{ND}}$ & $\lambda_{\mathrm{LD}}$ & $\sigma_{N L D}$ & \\
\hline \multirow{21}{*}{ 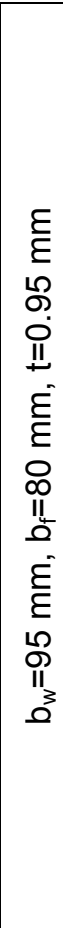 } & \multirow{3}{*}{11} & \multirow{3}{*}{650} & \multirow{3}{*}{ D } & 250 & \multirow{3}{*}{92} & \multirow{3}{*}{100} & 94 & $A$ & 1.58 & 123 & 1.16 & 95 & $\begin{array}{l}1.01 \\
\end{array}$ \\
\hline & & & & 350 & & & 95 & $A$ & 1.87 & 145 & 1.26 & 106 & 1.11 \\
\hline & & & & 550 & & & 99 & $A$ & 2.35 & 180 & 1.40 & 122 & 1.23 \\
\hline & \multirow{3}{*}{10.5} & \multirow{3}{*}{650} & \multirow{3}{*}{ D } & 250 & \multirow{3}{*}{92} & \multirow{3}{*}{96} & 91 & A & 1.62 & 121 & 1.15 & 94 & 1.03 \\
\hline & & & & 350 & & & 92 & A & 1.91 & 142 & 1.25 & 104 & 1.13 \\
\hline & & & & 550 & & & 97 & A & 2.40 & 176 & 1.39 & 120 & 1.24 \\
\hline & \multirow{3}{*}{10} & \multirow{3}{*}{600} & \multirow{3}{*}{ D } & 250 & \multirow{3}{*}{91} & \multirow{3}{*}{91} & 86 & A & 1.65 & 118 & 1.14 & 92 & 1.07 \\
\hline & & & & 350 & & & 87 & $A$ & 1.96 & 139 & 1.23 & 103 & 1.17 \\
\hline & & & & 550 & & & 92 & $A$ & 2.45 & 171 & 1.37 & 118 & 1.28 \\
\hline & \multirow{3}{*}{9.5} & \multirow{3}{*}{600} & \multirow{3}{*}{ D } & 250 & \multirow{3}{*}{91} & \multirow{3}{*}{87} & 83 & $A$ & 1.70 & 115 & 1.12 & 91 & 1.10 \\
\hline & & & & 350 & & & 84 & $A$ & 2.01 & 135 & 1.22 & 101 & 1.20 \\
\hline & & & & 550 & & & 91 & $B$ & 2.51 & 167 & 1.35 & 116 & 1.27 \\
\hline & \multirow{3}{*}{9} & \multirow{3}{*}{550} & \multirow{3}{*}{ D } & 250 & \multirow{3}{*}{91} & \multirow{3}{*}{83} & 78 & $A$ & 1.74 & 112 & 1.11 & 89 & 1.14 \\
\hline & & & & 350 & & & 79 & $A$ & 2.06 & 132 & 1.20 & 99 & 1.25 \\
\hline & & & & 550 & & & 84 & $A$ & 2.58 & 162 & 1.34 & 114 & 1.35 \\
\hline & \multirow{3}{*}{10.5} & & & 250 & & & 109 & $A$ & 1.62 & 121 & 1.15 & 94 & 0.86 \\
\hline & & 650 & LP & 350 & 92 & 96 & 109 & $A$ & 1.91 & 142 & 1.25 & 104 & 0.96 \\
\hline & & & & 550 & & & 109 & A & 2.40 & 176 & 1.39 & 120 & 1.10 \\
\hline & & & & 250 & & & 114 & A & 1.58 & 123 & 1.16 & 95 & 0.83 \\
\hline & 11 & 650 & LP & 350 & 92 & 100 & 114 & A & 1.87 & 145 & 1.26 & 106 & 0.93 \\
\hline & & & & 550 & & & 114 & $A$ & 2.35 & 180 & 1.40 & 122 & 1.07 \\
\hline
\end{tabular}


Table 2(a). Comparison Between the "Exact" and DSM $\left(\sigma_{N D L}\right)$ Ultimate Strength Estimates (SLC1)

\begin{tabular}{|c|c|c|c|c|c|c|c|c|c|c|c|c|c|}
\hline & \multirow{2}{*}{\multicolumn{4}{|c|}{ 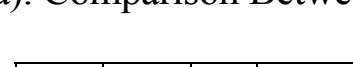 }} & \multirow{2}{*}{\multicolumn{4}{|c|}{ FEA }} & \multirow{2}{*}{\multicolumn{4}{|c|}{ DSM }} & \multirow{3}{*}{$\sigma_{N D L} / \sigma_{U}$} \\
\hline & & & & & & & & & & & & & \\
\hline & $b_{f}$ & $\mathrm{~L}$ & Imp. & $f_{y}$ & $\sigma_{\mathrm{L}}$ & $\sigma_{D}$ & $\sigma_{U}$ & Fail. & $\lambda_{L}$ & $\sigma_{\mathrm{NL}}$ & $\lambda_{\mathrm{DL}}$ & $\sigma_{\mathrm{NDL}}$ & \\
\hline \multirow{21}{*}{ 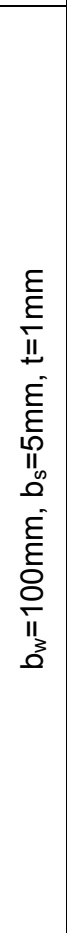 } & \multirow{3}{*}{55} & \multirow{3}{*}{300} & \multirow{3}{*}{ D } & 250 & \multirow{3}{*}{101} & \multirow{3}{*}{91} & 94 & $B$ & 1.58 & 156 & 1.31 & 92 & 0.98 \\
\hline & & & & 350 & & & 110 & $B$ & 1.86 & 193 & 1.46 & 103 & 0.94 \\
\hline & & & & 550 & & & 131 & A & 2.34 & 258 & 1.69 & 119 & 0.91 \\
\hline & \multirow{3}{*}{52.5} & \multirow{3}{*}{280} & \multirow{3}{*}{ D } & 250 & \multirow{3}{*}{101} & \multirow{3}{*}{96} & 97 & $B$ & 1.57 & 156 & 1.27 & 95 & 0.98 \\
\hline & & & & 350 & & & 114 & $\mathrm{~B}$ & 1.86 & 194 & 1.42 & 106 & 0.93 \\
\hline & & & & 550 & & & 137 & A & 2.33 & 258 & 1.64 & 123 & 0.90 \\
\hline & \multirow{3}{*}{50} & \multirow{3}{*}{270} & \multirow{3}{*}{$\mathrm{D}$} & 250 & \multirow{3}{*}{102} & \multirow{3}{*}{102} & 102 & $B$ & 1.57 & 156 & 1.24 & 97 & 0.96 \\
\hline & & & & 350 & & & 120 & $B$ & 1.85 & 194 & 1.38 & 109 & 0.91 \\
\hline & & & & 550 & & & 147 & A & 2.32 & 259 & 1.59 & 127 & 0.86 \\
\hline & \multirow{3}{*}{47.5} & \multirow{3}{*}{260} & \multirow{3}{*}{$\mathrm{D}$} & 250 & \multirow{3}{*}{102} & \multirow{3}{*}{108} & 107 & $B$ & 1.56 & 157 & 1.21 & 100 & 0.94 \\
\hline & & & & 350 & & & 127 & $B$ & 1.85 & 194 & 1.34 & 112 & 0.89 \\
\hline & & & & 550 & & & 156 & A & 2.32 & 259 & 1.55 & 130 & 0.84 \\
\hline & \multirow{3}{*}{45} & \multirow{3}{*}{260} & \multirow{3}{*}{$\mathrm{D}$} & 250 & \multirow{3}{*}{103} & \multirow{3}{*}{113} & 115 & $\mathrm{~B}$ & 1.56 & 157 & 1.18 & 103 & 0.89 \\
\hline & & & & 350 & & & 136 & $\mathrm{~B}$ & 1.84 & 195 & 1.31 & 115 & 0.85 \\
\hline & & & & 550 & & & 168 & A & 2.31 & 260 & 1.51 & 134 & 0.80 \\
\hline & & & & 250 & & & 118 & A & 1.56 & 157 & 1.21 & 100 & 0.85 \\
\hline & 47.5 & 260 & LP & 350 & 102 & 108 & 127 & B & 1.85 & 194 & 1.34 & 112 & 0.89 \\
\hline & & & & 550 & & & 157 & B & 2.32 & 259 & 1.55 & 130 & 0.83 \\
\hline & & & & 250 & & & 128 & A & 1.56 & 157 & 1.18 & 103 & 0.80 \\
\hline & 45 & 260 & LP & 350 & 103 & 113 & 142 & $B$ & 1.84 & 195 & 1.31 & 115 & 0.81 \\
\hline & & & & 550 & & & 168 & $B$ & 2.31 & 260 & 1.51 & 134 & 0.80 \\
\hline
\end{tabular}

Table 2(b). Comparison Between the "Exact" and DSM $\left(\sigma_{N D L}\right)$ Ultimate Strength Estimates (SLC2)

\begin{tabular}{|c|c|c|c|c|c|c|c|c|c|c|c|c|c|}
\hline & & & & & \multicolumn{4}{|c|}{ FEA } & \multicolumn{4}{|c|}{ DSM } & \multirow[b]{2}{*}{$\sigma_{\mathrm{NDL}} / \sigma_{\mathrm{U}}$} \\
\hline & $b_{w}$ & L & Imp. & $f_{y}$ & $\sigma_{\mathrm{L}}$ & $\sigma_{D}$ & $\sigma_{u}$ & Fail. & $\lambda_{L}$ & $\sigma_{N L}$ & $\lambda_{\mathrm{DL}}$ & $\sigma_{N D L}$ & \\
\hline \multirow{24}{*}{ 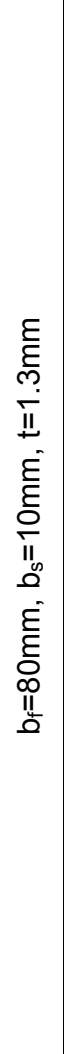 } & \multirow{3}{*}{130} & \multirow{3}{*}{550} & \multirow{3}{*}{ D } & 250 & \multirow{3}{*}{100} & \multirow{3}{*}{110} & 105 & $A$ & 1.58 & 155 & 1.19 & 101 & 0.96 \\
\hline & & & & 350 & & & 107 & B & 1.87 & 193 & 1.32 & 113 & 1.06 \\
\hline & & & & 550 & & & 123 & B & 2.35 & 257 & 1.53 & 131 & 1.07 \\
\hline & \multirow{3}{*}{125} & \multirow{3}{*}{550} & \multirow{3}{*}{ D } & 250 & \multirow{3}{*}{107} & \multirow{3}{*}{113} & 107 & A & 1.53 & 159 & 1.19 & 103 & 0.96 \\
\hline & & & & 350 & & & 109 & A & 1.81 & 198 & 1.32 & 116 & 1.06 \\
\hline & & & & 550 & & & 123 & B & 2.27 & 264 & 1.53 & 135 & 1.09 \\
\hline & \multirow{3}{*}{120} & \multirow{3}{*}{550} & \multirow{3}{*}{ D } & 250 & \multirow{3}{*}{115} & \multirow{3}{*}{115} & 109 & A & 1.47 & 163 & 1.19 & 106 & 0.97 \\
\hline & & & & 350 & & & 111 & A & 1.74 & 203 & 1.33 & 119 & 1.07 \\
\hline & & & & 550 & & & 124 & B & 2.18 & 271 & 1.53 & 138 & 1.11 \\
\hline & \multirow{3}{*}{115} & \multirow{3}{*}{550} & \multirow{3}{*}{ D } & 250 & \multirow{3}{*}{124} & \multirow{3}{*}{118} & 112 & $A$ & 1.42 & 168 & 1.19 & 108 & 0.97 \\
\hline & & & & 350 & & & 114 & A & 1.68 & 209 & 1.33 & 122 & 1.07 \\
\hline & & & & 550 & & & 122 & B & 2.10 & 278 & 1.53 & 142 & 1.16 \\
\hline & \multirow{3}{*}{110} & \multirow{3}{*}{550} & \multirow{3}{*}{ D } & 250 & \multirow{3}{*}{135} & \multirow{3}{*}{121} & 114 & A & 1.36 & 172 & 1.19 & 111 & 0.98 \\
\hline & & & & 350 & & & 116 & A & 1.61 & 214 & 1.33 & 125 & 1.08 \\
\hline & & & & 550 & & & 121 & A & 2.02 & 287 & 1.5 & 145 & 1.20 \\
\hline & & & & 250 & & & 119 & A & 1.26 & 182 & 1.20 & 117 & 0.98 \\
\hline & 100 & 550 & D & 350 & 157 & 127 & 122 & A & 1.49 & 226 & 1.34 & 132 & 1.08 \\
\hline & & & & 550 & & & 126 & A & 1.87 & 303 & 1.55 & 153 & 1.21 \\
\hline & & & & 250 & & & 119 & A & 1.53 & 159 & 1.19 & 103 & 0.87 \\
\hline & 125 & 550 & LP & 350 & 107 & 113 & 120 & A & 1.81 & 198 & 1.32 & 116 & 0.97 \\
\hline & & & & 550 & & & 122 & $B$ & 2.27 & 264 & 1.53 & 135 & 1.10 \\
\hline & & & & 250 & & & 120 & $A$ & 1.58 & 155 & 1.19 & 101 & 0.84 \\
\hline & 130 & 550 & LP & 350 & 100 & 110 & 121 & A & 1.87 & 193 & 1.32 & 113 & 0.93 \\
\hline & & & & 550 & & & 123 & $B$ & 2.35 & 257 & 1.53 & 131 & 1.07 \\
\hline
\end{tabular}


Table 2(c). Comparison Between the "Exact" and DSM $\left(\sigma_{N D L}\right)$ Ultimate Strength Estimates (SLC3)

\begin{tabular}{|c|c|c|c|c|c|c|c|c|c|c|c|c|c|}
\hline & \multirow{3}{*}{$\mathrm{b}_{\mathrm{s}}$} & & \multirow{2}{*}{\multicolumn{4}{|c|}{ FEA }} & \multirow{2}{*}{\multicolumn{4}{|c|}{ DSM }} & \multirow[b]{3}{*}{$\sigma_{N D L} / \sigma_{U}$} \\
\hline & & & & & & & & & & & & & \\
\hline & & L & Imp. & $f_{y}$ & $\sigma_{\mathrm{L}}$ & $\sigma_{D}$ & $\sigma_{u}$ & Fail. & $\lambda_{L}$ & $\sigma_{\mathrm{NL}}$ & $\lambda_{\mathrm{DL}}$ & $\sigma_{\mathrm{NDL}}$ & \\
\hline \multirow{21}{*}{ 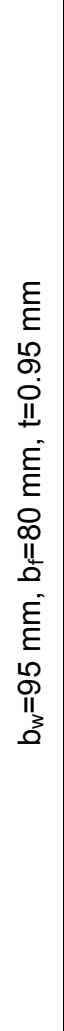 } & \multirow{3}{*}{11} & \multirow{3}{*}{650} & \multirow{3}{*}{ D } & 250 & \multirow{3}{*}{92} & \multirow{3}{*}{100} & 94 & A & 1.65 & 150 & 1.23 & 95 & 1.00 \\
\hline & & & & 350 & & & 95 & A & 1.96 & 187 & 1.37 & 106 & 1.12 \\
\hline & & & & 550 & & & 99 & A & 2.45 & 249 & 1.58 & 123 & 1.24 \\
\hline & \multirow{3}{*}{10.5} & \multirow{3}{*}{650} & \multirow{3}{*}{ D } & 250 & \multirow{3}{*}{92} & \multirow{3}{*}{96} & 91 & A & 1.65 & 150 & 1.25 & 93 & 1.02 \\
\hline & & & & 350 & & & 92 & $A$ & 1.96 & 187 & 1.40 & 104 & 1.13 \\
\hline & & & & 550 & & & 97 & A & 2.45 & 249 & 1.61 & 120 & 1.24 \\
\hline & \multirow{3}{*}{10} & \multirow{3}{*}{600} & \multirow{3}{*}{ D } & 250 & \multirow{3}{*}{91} & \multirow{3}{*}{91} & 86 & A & 1.65 & 150 & 1.28 & 91 & 1.05 \\
\hline & & & & 350 & & & 87 & A & 1.96 & 187 & 1.43 & 102 & 1.17 \\
\hline & & & & 550 & & & 92 & A & 2.45 & 249 & 1.65 & 118 & 1.28 \\
\hline & \multirow{3}{*}{9.5} & \multirow{3}{*}{600} & \multirow{3}{*}{ D } & 250 & \multirow{3}{*}{91} & \multirow{3}{*}{87} & 83 & $A$ & 1.66 & 150 & 1.31 & 89 & 1.08 \\
\hline & & & & 350 & & & 84 & A & 1.96 & 187 & 1.46 & 99 & 1.19 \\
\hline & & & & 550 & & & 91 & $B$ & 2.46 & 248 & 1.69 & 115 & 1.26 \\
\hline & \multirow{3}{*}{9} & \multirow{3}{*}{550} & \multirow{3}{*}{ D } & 250 & \multirow{3}{*}{91} & & 78 & $A$ & 1.66 & 150 & 1.35 & 87 & 1.11 \\
\hline & & & & 350 & & 83 & 79 & A & 1.96 & 186 & 1.50 & 97 & 1.22 \\
\hline & & & & 550 & & & 84 & A & 2.46 & 248 & 1.73 & 112 & 1.33 \\
\hline & & & & 250 & & & 109 & A & 1.65 & 150 & 1.25 & 93 & 0.85 \\
\hline & 10.5 & 650 & LP & 350 & 92 & 96 & 109 & A & 1.96 & 187 & 1.40 & 104 & 0.95 \\
\hline & & & & 550 & & & 109 & A & 2.45 & 249 & 1.61 & 120 & 1.10 \\
\hline & & & & 250 & & & 114 & A & 1.65 & 150 & 1.23 & 95 & 0.83 \\
\hline & 11 & 650 & LP & 350 & 92 & 100 & 114 & A & 1.96 & 187 & 1.37 & 106 & 0.93 \\
\hline & & & & 550 & & & 114 & A & 2.45 & 249 & 1.58 & 123 & 1.08 \\
\hline
\end{tabular}

\section{ASSESSMENT OF THE DSM ESTIMATES}

The numerical and DSM results given in Tables 1 and 2 concern the 66 slender columns analysed (geometries SLC1, SLC2 and SLC3) and enable the comparison between the "exact" ultimate strengths $\left(\sigma_{U}=P_{U} / A\right)$ and the estimates yielded by the two proposed DSM approaches, namely $\sigma_{N D L}=P_{N D L} / A$ and $\sigma_{N L D}=P_{N L D} / A$ - also indicated are the values of the $\sigma_{N D}$ and $\sigma_{N L}$ estimates. The observation of the results presented in these two tables prompts the following remarks:

(i) The $\sigma_{U}$ values concerning local-plate (LP) imperfections never fall below their distortional (D) counterparts, thus confirming that the distortional imperfections are the most detrimental ones. As the DSM does not capture the effect of the imperfection shape, its estimates should preferably approximate well the $\sigma_{U}$ values concerning the D imperfections. If this is the case, then the DSM estimates will be more or less conservative for columns containing LP imperfection components.

(ii) The $\sigma_{N D L}$ and $\sigma_{N L D}$ estimates are very similar, even if the "quality" of the former is slightly higher the $\sigma_{N D L} / \sigma_{U}$ and $\sigma_{N L D} / \sigma_{U}$ means and standard deviations are 1.01 vs. 1.02 and 0.13 vs. 0.14 . Although the whole sets of $\sigma_{N D L}$ and $\sigma_{N L D}$ estimates may be viewed as quite accurate (means very close to 1.00), one must also recognise that their scatters are rather high (standard deviations above 0.12 ).

(iii) Out of the $66 \sigma_{N D L}$ estimates, 1 is exact, 19 are safe and accurate $\left(\sigma_{N D L} / \sigma_{U} \geq 0.9\right), 16$ are too safe $\left(0.80 \leq \sigma_{N L D} / \sigma_{U}<0.90\right), 15$ are a bit unsafe $\left(\sigma_{N D L} / \sigma_{U} \leq 1.10\right)$ and 15 are too unsafe $\left(1.10<\sigma_{N D L}\right.$ $\left./ \sigma_{U} \leq 1.33\right)$. 
(iv) Out of the $66 \sigma_{N L D}$ estimates, 1 is exact, 16 are safe and accurate $\left(\sigma_{N L D} / \sigma_{U} \geq 0.9\right), 15$ are too safe $\left(0.79 \leq \sigma_{N L D} / \sigma_{U}<0.90\right), 17$ are a bit unsafe $\left(\sigma_{N L D} / \sigma_{U} \leq 1.10\right)$ and 17 are too unsafe $\left(1.10<\sigma_{N L D}\right.$ $\left./ \sigma_{U} \leq 1.35\right)$.

(v) Both the local-plate $\left(\sigma_{N L}\right)$ and distortional $\left(\sigma_{N D}\right)$ DSM expressions clearly overestimate the ultimate strengths $\left(\sigma_{U}\right)$ of the slender columns affected by local-plate/distortional mode interaction.

As for Tables 3 and 4, they display similar numerical $\left(\sigma_{U}=P_{U} / A\right)$ and DSM $\left(\sigma_{N D L}=P_{N D L} / A, \sigma_{N L D}=P_{N L D}\right.$ IA) results for the 45 stocky columns considered in this study (geometries STC1, STC2 and STC3). The observation of these results leads to the following comments:

(i) Although the $\sigma_{N D L}$ and $\sigma_{N L D}$ estimates are once more very similar, the slightly higher "quality" belongs this time to the latter - the $\sigma_{N D L} / \sigma_{U}$ and $\sigma_{N L D} / \sigma_{U}$ means and standard deviations are $0.88 \mathrm{vs}$. 0.90 and 0.061 vs. 0.057 . One notices that the whole sets of $\sigma_{N D L}$ and $\sigma_{N L D}$ estimates are now a bit conservative (means around 0.90 ), but exhibit relatively low scatters (standard deviations around 0.06 ) - moreover, there are no unsafe predictions at all.

(ii) Out of the $45 \sigma_{N L D}$ estimates, 24 are both safe and accurate $\left(\sigma_{N L D} / \sigma_{U} \geq 0.9\right)$ and 21 are excessively safe $\left(0.80 \leq \sigma_{N L D} / \sigma_{U}<0.90\right)$.

(iii) Out of the $45 \sigma_{N D L}$ estimates, 19 are both safe and accurate $\left(\sigma_{N D L} / \sigma_{U} \geq 0.9\right)$ and 26 are excessively unsafe $\left(0.78 \leq \sigma_{N L D} / \sigma_{U}<0.90\right)$.

(iv) Unlike in the case of the slender columns, the distortional DSM expressions $\left(\sigma_{N D}\right)$ now provide reasonably accurate ultimate strength estimates for the stocky columns affected by local-plate/distortional interaction - indeed, only in 8 columns (out of 45), all of them concerning the higher yield stress $\left(f_{y}=550 \mathrm{MPa}\right)$, are the $\sigma_{N D}$ estimates larger than the $\sigma_{U}$ values. Conversely, the local-plate DSM expressions $\left(\sigma_{N L}\right)$ often lead mostly to an overestimation of the stocky column $\sigma_{U}$ values - only in 10 columns do the $\sigma_{N L}$ values fall below the $\sigma_{U}$ ones.

In view of the facts outlined and explained above, the authors believe that the $\sigma_{N L D}$ approach is superior to the $\sigma_{N D L}$ one (although the differences are not at all substantial) - therefore, the results presented hereafter are based on the assumption that the $\sigma_{N L D}$ approach is adopted. In this context, Figures. 9 (slender columns) and 10 (stocky columns) make it possible to assess how the stress ratios $\sigma_{C R D} / \sigma_{C R L}$ and $\sigma_{N L D} / \sigma_{U}$ vary with the cross-section dimensions $b_{f}, b_{w}, b_{s}$ - the latter for $f_{y}=250,350,550 \mathrm{MPa}$. From the observation of these two figures, one readily concludes that:

(i) Both the slender and stocky columns have stress ratios $\sigma_{C R D} / \sigma_{C R L}$ and $\sigma_{N L D} / \sigma_{U}$ that always exhibit opposite variations with the cross-section dimensions - this suggests that the $\sigma_{C R D} / \sigma_{C R L}$ value may be used to improve the $\sigma_{N L D}$ estimates (and also the $\sigma_{N D L}$ ones, for that matter).

(ii) The slender column $\sigma_{N L D}$ estimates are all safe in the first plots, mostly unsafe in the second and almost all unsafe in the third. This "safety drop" is most likely related to the $b_{f} / b_{w}$ ratio increase: $0.45-0.55$ (first plot), 0.61-0.73 (second) and 0.84-0.84 (third). 
Table 3(a). Comparison Between the "Exact" and DSM $\left(\sigma_{N L D}\right)$ Ultimate Strength Estimates (STC1)

\begin{tabular}{|c|c|c|c|c|c|c|c|c|c|c|c|c|}
\hline & & & & & & FEA & & & & & & \\
\hline & $b_{f}$ & L & Imp. & $f_{y}$ & $\sigma_{\mathrm{CRL}}$ & $\sigma_{\mathrm{CRD}}$ & $\sigma_{U}$ & $\lambda_{D}$ & $\sigma_{\mathrm{ND}}$ & $\lambda_{L D}$ & $\sigma_{\mathrm{NLD}}$ & $\sigma_{N L D} / \sigma_{U}$ \\
\hline \multirow{15}{*}{$\begin{array}{l}\varepsilon \\
\varepsilon \\
f \\
\tilde{D} \\
\mathbb{1} \\
\dot{E}\end{array}$} & \multirow{3}{*}{90} & \multirow{3}{*}{650} & \multirow{3}{*}{ D } & 250 & \multirow{3}{*}{361} & \multirow{3}{*}{399} & 240 & 0.79 & 221 & 0.78 & 220 & 0.92 \\
\hline & & & & 350 & & & 298 & 0.94 & 276 & 0.87 & 256 & 0.86 \\
\hline & & & & 550 & & & 361 & 1.17 & 360 & 1.00 & 306 & 0.85 \\
\hline & \multirow{3}{*}{95} & \multirow{3}{*}{650} & \multirow{3}{*}{ D } & 250 & \multirow{3}{*}{358} & \multirow{3}{*}{377} & 231 & 0.81 & 218 & 0.78 & 217 & 0.94 \\
\hline & & & & 350 & & & 287 & 0.96 & 270 & 0.87 & 252 & 0.88 \\
\hline & & & & 550 & & & 341 & 1.21 & 351 & 0.99 & 300 & 0.88 \\
\hline & \multirow{3}{*}{100} & \multirow{3}{*}{650} & \multirow{3}{*}{ D } & 250 & \multirow{3}{*}{355} & \multirow{3}{*}{355} & 222 & 0.84 & 213 & 0.78 & 213 & 0.96 \\
\hline & & & & 350 & & & 276 & 0.99 & 264 & 0.86 & 247 & 0.90 \\
\hline & & & & 550 & & & 323 & 1.24 & 342 & 0.98 & 294 & 0.91 \\
\hline & \multirow{3}{*}{105} & \multirow{3}{*}{650} & \multirow{3}{*}{ D } & 250 & \multirow{3}{*}{353} & \multirow{3}{*}{338} & 217 & 0.86 & 210 & 0.77 & 210 & 0.97 \\
\hline & & & & 350 & & & 267 & 1.02 & 259 & 0.86 & 243 & 0.91 \\
\hline & & & & 550 & & & 307 & 1.28 & 334 & 0.97 & 289 & 0.94 \\
\hline & \multirow{3}{*}{110} & \multirow{3}{*}{650} & \multirow{3}{*}{ D } & 250 & \multirow{3}{*}{350} & \multirow{3}{*}{320} & 211 & 0.88 & 206 & 0.77 & 206 & 0.98 \\
\hline & & & & 350 & & & 256 & 1.04 & 253 & 0.85 & 239 & 0.93 \\
\hline & & & & 550 & & & 292 & 1.31 & 326 & 0.96 & 284 & 0.97 \\
\hline
\end{tabular}

Table 3(b). Comparison Between the "Exact" and DSM $\left(\sigma_{N L D}\right)$ Ultimate Strength Estimates (STC2)

\begin{tabular}{|c|c|c|c|c|c|c|c|c|c|c|c|c|}
\hline & & & & & \multicolumn{3}{|c|}{ FEA } & \multicolumn{4}{|c|}{ DSM } & \\
\hline & $b_{f}$ & L & Imp & $f_{y}$ & $\sigma_{C R L}$ & $\sigma_{\mathrm{CRD}}$ & $\sigma_{u}$ & $\lambda_{D}$ & $\sigma_{\mathrm{ND}}$ & $\lambda_{\mathrm{LD}}$ & $\sigma_{N L D}$ & $\sigma_{N L D} / \sigma_{U}$ \\
\hline \multirow{15}{*}{ 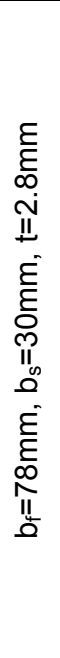 } & \multirow{3}{*}{100} & \multirow{3}{*}{800} & \multirow{3}{*}{ D } & 250 & \multirow{3}{*}{736} & \multirow{3}{*}{656} & 249 & 0.62 & 247 & 0.58 & 247 & $\begin{array}{l}0.99 \\
\end{array}$ \\
\hline & & & & 350 & & & 345 & 0.73 & 324 & 0.66 & 324 & 0.94 \\
\hline & & & & 550 & & & 508 & 0.92 & 442 & 0.77 & 442 & 0.87 \\
\hline & \multirow{3}{*}{105} & \multirow{3}{*}{800} & \multirow{3}{*}{ D } & 250 & \multirow{3}{*}{680} & \multirow{3}{*}{641} & 249 & 0.62 & 246 & 0.60 & 246 & 0.99 \\
\hline & & & & 350 & & & 344 & 0.74 & 322 & 0.69 & 322 & 0.94 \\
\hline & & & & 550 & & & 503 & 0.93 & 438 & 0.80 & 429 & 0.85 \\
\hline & \multirow{3}{*}{110} & \multirow{3}{*}{800} & \multirow{3}{*}{ D } & 250 & \multirow{3}{*}{630} & \multirow{3}{*}{625} & 248 & 0.63 & 246 & 0.62 & 246 & 0.99 \\
\hline & & & & 350 & & & 344 & 0.75 & 320 & 0.71 & 320 & 0.93 \\
\hline & & & & 550 & & & 499 & 0.94 & 434 & 0.83 & 416 & 0.83 \\
\hline & \multirow{3}{*}{115} & \multirow{3}{*}{800} & \multirow{3}{*}{ D } & 250 & \multirow{3}{*}{581} & \multirow{3}{*}{611} & 248 & 0.64 & 245 & 0.65 & 245 & 0.99 \\
\hline & & & & 350 & & & 342 & 0.76 & 318 & 0.74 & 318 & 0.93 \\
\hline & & & & 550 & & & 493 & 0.95 & 430 & 0.86 & 403 & 0.82 \\
\hline & \multirow{3}{*}{120} & \multirow{3}{*}{800} & \multirow{3}{*}{ D } & 250 & \multirow{3}{*}{538} & \multirow{3}{*}{596} & 248 & 0.65 & 244 & 0.67 & 244 & 0.98 \\
\hline & & & & 350 & & & 341 & 0.77 & 316 & 0.77 & 316 & 0.93 \\
\hline & & & & 550 & & & 489 & 0.96 & 426 & 0.89 & 391 & 0.80 \\
\hline
\end{tabular}

Table 3(c). Comparison Between the "Exact" and DSM $\left(\sigma_{N L D}\right)$ Ultimate Strength Estimates (STC3)

\begin{tabular}{|c|c|c|c|c|c|c|c|c|c|c|c|c|}
\hline & & & & & \multicolumn{3}{|c|}{ FEA } & \multicolumn{4}{|c|}{ DSM } & \multirow[b]{2}{*}{$\sigma_{N L D} / \sigma_{U}$} \\
\hline & $b_{f}$ & L & Imp. & $f_{y}$ & $\sigma_{C R L}$ & $\sigma_{\mathrm{CRD}}$ & $\sigma_{u}$ & $\lambda_{D}$ & $\sigma_{\mathrm{ND}}$ & $\lambda_{\mathrm{LD}}$ & $\sigma_{N L D}$ & \\
\hline \multirow{15}{*}{$\begin{array}{l}\varepsilon \\
\varepsilon \\
8\end{array}$} & \multirow{3}{*}{22} & \multirow{3}{*}{950} & \multirow{3}{*}{ D } & 250 & \multirow{3}{*}{317} & \multirow{3}{*}{285} & 226 & 0.94 & 197 & 0.79 & 195 & \begin{tabular}{|l|}
0.86 \\
\end{tabular} \\
\hline & & & & 350 & & & 262 & 1.11 & 241 & 0.87 & 224 & 0.85 \\
\hline & & & & 550 & & & 276 & 1.39 & 308 & 0.99 & 265 & 0.96 \\
\hline & \multirow{3}{*}{24} & \multirow{3}{*}{950} & \multirow{3}{*}{ D } & 250 & \multirow{3}{*}{317} & \multirow{3}{*}{299} & 227 & 0.92 & 201 & 0.80 & 198 & 0.87 \\
\hline & & & & 350 & & & 270 & 1.08 & 246 & 0.88 & 227 & 0.84 \\
\hline & & & & 550 & & & 287 & 1.36 & 315 & 1.00 & 268 & 0.94 \\
\hline & \multirow{3}{*}{26} & \multirow{3}{*}{950} & \multirow{3}{*}{ D } & 250 & \multirow{3}{*}{317} & \multirow{3}{*}{314} & 230 & 0.89 & 205 & 0.80 & 200 & 0.87 \\
\hline & & & & 350 & & & 279 & 1.06 & 251 & 0.89 & 230 & 0.83 \\
\hline & & & & 550 & & & 300 & 1.32 & 323 & 1.01 & 273 & 0.91 \\
\hline & \multirow{3}{*}{28} & \multirow{3}{*}{950} & \multirow{3}{*}{ D } & 250 & \multirow{3}{*}{316} & \multirow{3}{*}{331} & 232 & 0.87 & 208 & 0.81 & 202 & 0.87 \\
\hline & & & & 350 & & & 288 & 1.03 & 257 & 0.90 & 233 & 0.81 \\
\hline & & & & 550 & & & 316 & 1.29 & 331 & 1.02 & 277 & 0.88 \\
\hline & \multirow{3}{*}{30} & \multirow{3}{*}{950} & \multirow{3}{*}{ D } & 250 & \multirow{3}{*}{315} & \multirow{3}{*}{350} & 234 & 0.85 & 212 & 0.82 & 205 & 0.88 \\
\hline & & & & 350 & & & 297 & 1.00 & 263 & 0.91 & 237 & 0.80 \\
\hline & & & & 550 & & & 337 & 1.25 & 339 & 1.04 & 281 & 0.83 \\
\hline
\end{tabular}


Table 4(a). Comparison Between the "Exact" and DSM $\left(\sigma_{N D L}\right)$ Ultimate Strength Estimates (STC1)

\begin{tabular}{|c|c|c|c|c|c|c|c|c|c|c|c|c|}
\hline & & & & & & FEA & & & & & & \\
\hline & $b_{f}$ & $\mathrm{~L}$ & Imp. & $f_{y}$ & $\sigma_{\mathrm{CRL}}$ & $\sigma_{\mathrm{CRD}}$ & $\sigma_{u}$ & $\lambda_{L}$ & $\sigma_{\mathrm{NL}}$ & $\lambda_{\mathrm{DL}}$ & $\sigma_{\mathrm{NDL}}$ & $\sigma_{N D L} / \sigma_{U}$ \\
\hline \multirow{15}{*}{$\begin{array}{l}\varepsilon \\
\varepsilon \\
\xi \\
\tilde{N} \\
\mathbb{1}\end{array}$} & \multirow{3}{*}{90} & \multirow{3}{*}{650} & \multirow{3}{*}{ D } & 250 & \multirow{3}{*}{361} & \multirow{3}{*}{399} & 240 & 0.83 & 239 & 0.77 & 215 & 0.89 \\
\hline & & & & 350 & & & 298 & 0.98 & 301 & 0.87 & 251 & 0.84 \\
\hline & & & & 550 & & & 361 & 1.23 & 406 & 1.01 & 302 & 0.84 \\
\hline & \multirow{3}{*}{95} & \multirow{3}{*}{650} & \multirow{3}{*}{ D } & 250 & \multirow{3}{*}{358} & \multirow{3}{*}{377} & 231 & 0.84 & 239 & 0.80 & 211 & 0.91 \\
\hline & & & & 350 & & & 287 & 0.99 & 300 & 0.89 & 245 & 0.85 \\
\hline & & & & 550 & & & 341 & 1.24 & 405 & 1.04 & 295 & 0.86 \\
\hline & \multirow{3}{*}{100} & \multirow{3}{*}{650} & \multirow{3}{*}{ D } & 250 & \multirow{3}{*}{355} & \multirow{3}{*}{355} & 222 & 0.84 & 238 & 0.82 & 206 & 0.93 \\
\hline & & & & 350 & & & 276 & 0.99 & 299 & 0.92 & 240 & 0.87 \\
\hline & & & & 550 & & & 323 & 1.24 & 404 & 1.07 & 287 & 0.89 \\
\hline & \multirow{3}{*}{105} & \multirow{3}{*}{650} & \multirow{3}{*}{ D } & 250 & \multirow{3}{*}{353} & \multirow{3}{*}{338} & 217 & 0.84 & 238 & 0.84 & 203 & 0.93 \\
\hline & & & & 350 & & & 267 & 1.00 & 298 & 0.94 & 235 & 0.88 \\
\hline & & & & 550 & & & 307 & 1.25 & 403 & 1.09 & 281 & 0.91 \\
\hline & \multirow{3}{*}{110} & \multirow{3}{*}{650} & \multirow{3}{*}{ D } & 250 & \multirow{3}{*}{350} & \multirow{3}{*}{320} & 211 & 0.84 & 237 & 0.86 & 199 & 0.94 \\
\hline & & & & 350 & & & 256 & 1.00 & 298 & 0.96 & 230 & 0.90 \\
\hline & & & & 550 & & & 292 & 1.25 & 402 & 1.12 & 274 & 0.94 \\
\hline
\end{tabular}

Table 4(b). Comparison Between the "Exact" and DSM $\left(\sigma_{N D L}\right)$ Ultimate Strength Estimates (STC2)

\begin{tabular}{|c|c|c|c|c|c|c|c|c|c|c|c|c|}
\hline & & & & & \multicolumn{3}{|c|}{ FEA } & \multicolumn{4}{|c|}{ DSM } & \\
\hline & $b_{w}$ & $L$ & Imp. & $f_{y}$ & $\sigma_{\mathrm{CRL}}$ & $\sigma_{\mathrm{CRD}}$ & $\sigma_{u}$ & $\lambda_{L}$ & $\sigma_{N L}$ & $\lambda_{\mathrm{DL}}$ & $\sigma_{\mathrm{NDL}}$ & $\sigma_{\mathrm{NDL}} / \sigma_{U}$ \\
\hline \multirow{15}{*}{ 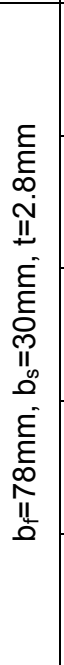 } & \multirow{3}{*}{100} & \multirow{3}{*}{800} & \multirow{3}{*}{ D } & 250 & \multirow{3}{*}{736} & \multirow{3}{*}{656} & 249 & 0.58 & 250 & 0.62 & 247 & \begin{tabular}{|l|} 
\\
\end{tabular} \\
\hline & & & & 350 & & & 345 & 0.69 & 350 & 0.73 & 324 & 0.94 \\
\hline & & & & 550 & & & 508 & 0.86 & 514 & 0.88 & 423 & 0.83 \\
\hline & \multirow{3}{*}{105} & \multirow{3}{*}{800} & \multirow{3}{*}{ D } & 250 & \multirow{3}{*}{680} & \multirow{3}{*}{641} & 249 & 0.61 & 250 & 0.62 & 246 & 0.99 \\
\hline & & & & 350 & & & 344 & 0.72 & 350 & 0.74 & 322 & 0.94 \\
\hline & & & & 550 & & & 503 & 0.90 & 501 & 0.88 & 412 & 0.82 \\
\hline & \multirow{3}{*}{110} & \multirow{3}{*}{800} & \multirow{3}{*}{ D } & 250 & \multirow{3}{*}{630} & \multirow{3}{*}{625} & 248 & 0.63 & 250 & 0.63 & 246 & 0.99 \\
\hline & & & & 350 & & & 344 & 0.75 & 350 & 0.75 & 320 & 0.93 \\
\hline & & & & 550 & & & 499 & 0.93 & 489 & 0.88 & 402 & 0.81 \\
\hline & \multirow{3}{*}{115} & \multirow{3}{*}{800} & \multirow{3}{*}{ D } & 250 & \multirow{3}{*}{581} & \multirow{3}{*}{611} & 248 & 0.66 & 250 & 0.64 & 245 & 0.99 \\
\hline & & & & 350 & & & 342 & 0.78 & 350 & 0.76 & 318 & 0.93 \\
\hline & & & & 550 & & & 493 & 0.97 & 476 & 0.88 & 392 & 0.80 \\
\hline & \multirow{3}{*}{120} & \multirow{3}{*}{800} & \multirow{3}{*}{ D } & 250 & \multirow{3}{*}{538} & \multirow{3}{*}{596} & 248 & 0.68 & 250 & 0.65 & 244 & 0.98 \\
\hline & & & & 350 & & & 341 & 0.81 & 342 & 0.76 & 311 & 0.91 \\
\hline & & & & 550 & & & 489 & 1.01 & 464 & 0.88 & 383 & 0.78 \\
\hline
\end{tabular}

Table 4(c). Comparison Between the "Exact" and DSM $\left(\sigma_{N D L}\right)$ Ultimate Strength Estimates (STC3)

\begin{tabular}{|c|c|c|c|c|c|c|c|c|c|c|c|c|}
\hline & & & & & \multicolumn{3}{|c|}{ FEA } & \multicolumn{4}{|c|}{ DSM } & \\
\hline & $b_{s}$ & L & Imp. & $f_{y}$ & $\sigma_{\mathrm{CRL}}$ & $\sigma_{\mathrm{CRD}}$ & $\sigma_{U}$ & $\lambda_{L}$ & $\sigma_{\mathrm{NL}}$ & $\lambda_{\mathrm{DL}}$ & $\sigma_{\mathrm{NDL}}$ & $\sigma_{N D L} / \sigma_{U}$ \\
\hline \multirow{15}{*}{$\begin{array}{l}\varepsilon \\
\text { ₹ } \\
\text { I }\end{array}$} & \multirow{3}{*}{22} & \multirow{3}{*}{950} & \multirow{3}{*}{ D } & 250 & \multirow{3}{*}{317} & \multirow{3}{*}{285} & 226 & 0.89 & 230 & 0.90 & 187 & 0.83 \\
\hline & & & & 350 & & & 262 & 1.05 & 288 & 1.00 & 215 & 0.82 \\
\hline & & & & 550 & & & 276 & 1.32 & 388 & 1.17 & 256 & 0.93 \\
\hline & \multirow{3}{*}{24} & \multirow{3}{*}{950} & \multirow{3}{*}{ D } & 250 & \multirow{3}{*}{317} & \multirow{3}{*}{299} & 227 & 0.89 & 230 & 0.88 & 190 & 0.84 \\
\hline & & & & 350 & & & 270 & 1.05 & 288 & 0.98 & 219 & 0.81 \\
\hline & & & & 550 & & & 287 & 1.32 & 388 & 1.14 & 261 & 0.91 \\
\hline & \multirow{3}{*}{26} & \multirow{3}{*}{950} & \multirow{3}{*}{ D } & 250 & \multirow{3}{*}{317} & \multirow{3}{*}{314} & 230 & 0.89 & 229 & 0.85 & 193 & 0.84 \\
\hline & & & & 350 & & & 279 & 1.05 & 288 & 0.96 & 223 & 0.80 \\
\hline & & & & 550 & & & 300 & 1.32 & 388 & 1.11 & 267 & 0.89 \\
\hline & \multirow{3}{*}{28} & \multirow{3}{*}{950} & \multirow{3}{*}{ D } & 250 & \multirow{3}{*}{316} & \multirow{3}{*}{331} & 232 & 0.89 & 229 & 0.83 & 197 & 0.85 \\
\hline & & & & 350 & & & 288 & 1.05 & 288 & 0.93 & 228 & 0.79 \\
\hline & & & & 550 & & & 316 & 1.32 & 388 & 1.08 & 273 & 0.86 \\
\hline & \multirow{3}{*}{30} & \multirow{3}{*}{950} & \multirow{3}{*}{ D } & 250 & \multirow{3}{*}{315} & \multirow{3}{*}{350} & 234 & 0.89 & 229 & 0.81 & 200 & 0.86 \\
\hline & & & & 350 & & & 297 & 1.05 & 287 & 0.91 & 232 & 0.78 \\
\hline & & & & 550 & & & 337 & 1.32 & 387 & 1.05 & 279 & 0.83 \\
\hline
\end{tabular}


(iii) While in the slender columns with narrow flanges (first plot) a $f_{y}$ increase leads to a $\sigma_{N L D} / \sigma_{U}$ drop (i.e., to safer but less accurate estimates), precisely the opposite behaviour is exhibited by the slender columns with moderate-to-wide flanges (second and third plots): a higher $f_{y}$ leads to a $\sigma_{N L D} / \sigma_{U}$ increase (i.e., to more unsafe results). Thus, the DSM estimate accuracy always drops as $f_{y}$ increases.

(iii) While in the slender columns with narrow flanges (first plot) a $f_{y}$ increase leads to a $\sigma_{N L D} / \sigma_{U}$ drop (i.e., to safer but less accurate estimates), precisely the opposite behaviour is exhibited by the slender columns with moderate-to-wide flanges (second and third plots): a higher $f_{y}$ leads to a $\sigma_{N L D} / \sigma_{U}$ increase (i.e., to more unsafe results). Therefore, it seems logical to assume that the DSM estimate accuracy always drops as the yield stress $f_{y}$ increases.

(iv) The stocky column $\sigma_{N L D}$ estimates are always safe in all the three plots - unlike in the slender columns, an increase of the $b_{f} / b_{w}$ ratio does not lead to unsafe estimates.

(v) In stocky columns with moderate flanges (second plot), a $f_{y}$ increase leads to a $\sigma_{N L D} / \sigma_{U}$ drop (i.e., to safer but less accurate results). Conversely, in stocky columns with narrow or wide flanges (first and third plots), there is no visible tendency, as far as the influence of $f_{y}$ on the safety level of the $\sigma_{N L D}$ estimates is concerned.

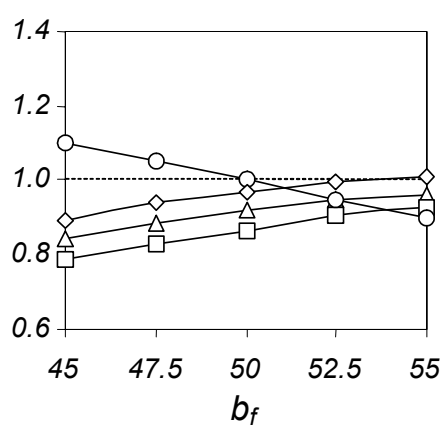

Figure 9. Slender Columns: Variation of $\sigma_{C R D} / \sigma_{C R L}$ and $\sigma_{N L D} / \sigma_{U}$

Ratios with the Cross-Section Dimensions

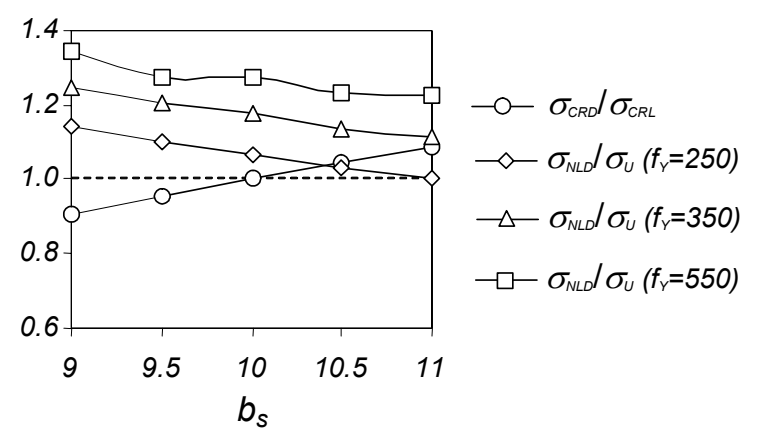


(i) For the slender columns, it is clear that an increase in $b_{f} / b_{w}$ always leads to an increase in the value of the stress ratio $\sigma_{N L D} / \sigma_{U}$. Moreover, the $\sigma_{N L D}$ estimates are (i $\left.i_{1}\right)$ mostly safe for columns with narrow flanges $\left(b_{f} / b_{w}<0.6\right)$ and ( $\left.\mathrm{i}_{2}\right)$ mostly unsafe for columns with moderate-to-wide flanges $\left(b_{f} / b_{w}>0.6\right)$.

(ii) For the stocky columns, a $b_{f} f b_{w}$ increase does not cause a similar increase in the stress ratio $\sigma_{N L D} / \sigma_{U}$.

(iii) In slender columns, a $f_{y}$ increase leads to a spreading of the $\sigma_{N L D} / \sigma_{U}$ values around (above and below) 1.0 - see Figure. 11(b). In stocky columns, on the other hand, a higher yield stress does not alter significantly the scatter of the $\sigma_{N L D} / \sigma_{U}$ vaules.

(iv) In columns with moderate-to-wide flanges, the LPM is triggered by the flange (not the web) instability. Since the DM is always caused by the flange-stiffener/lip instability, the flange local-plate deformations will certainly have a deteriorating effect on the column distortional post-buckling behaviour.

(v) Whenever the yield stress $f_{y}$ is much higher than the $\sigma_{C R D}$ and $\sigma_{C R L}$ values (this is the case in the slender columns with moderate-to-wide flanges and $f_{y}=550 \mathrm{MPa}$ ), there is lots of "room" for the local-plate/distortional mode interaction to develop before the applied stresses reach their ultimate value $\sigma_{U}$. This feature will certainly have a weakening impact on the ultimate strength of the columns affected by LP/D mode interaction.

Finally, Figure. 12 shows the variation of the $\sigma_{U} / f_{y}$ (white dots) and $\sigma_{N L D} / f_{y}$ (black dots) stress ratios with the columns distortional slenderness $\lambda_{D}=\left(f_{y} / \sigma_{C R D}\right)^{0.5}$, for the three yield stress values. Also included are the two DSM "Winter-type" curves providing the local-plate and distortional column ultimate strengths, which were defined in Eqs. 3 and 4. The joint observation of all these results prompts the following comments:

(i) The proposed DSM predictions $\left(\sigma_{N L D}\right)$ concerning the slender columns $\left(\lambda_{D}>1.4\right)$ always lie well below both the local-plate and distortional DSM curves. On the other hand, these same predictions for the stocky columns $\left(\lambda_{D}<1.4\right)$ are always located near the distortional DSM curve. This means that, at least for the critical stress ratio range considered $\left(0.90 \leq \sigma_{C R D} / \sigma_{C R L} \leq 1.10\right)$, the local-plate/distortional interaction always causes a substantial strength erosion in the slender columns (with respect to the values associated with the individual local-plate and distortional collapses).

(ii) Unlike the $\sigma_{N L D}$ estimates, which always remain quite "aligned" (i.e., define a single curve), the "exact" ultimate strengths exhibit a "vertical dispersion" that grows with $f_{y}$. This trait indicates that, as $f_{y}$ increases, the column $\sigma_{U}$ values become "more dependent" on the value of the slenderness $\lambda_{D}$. 


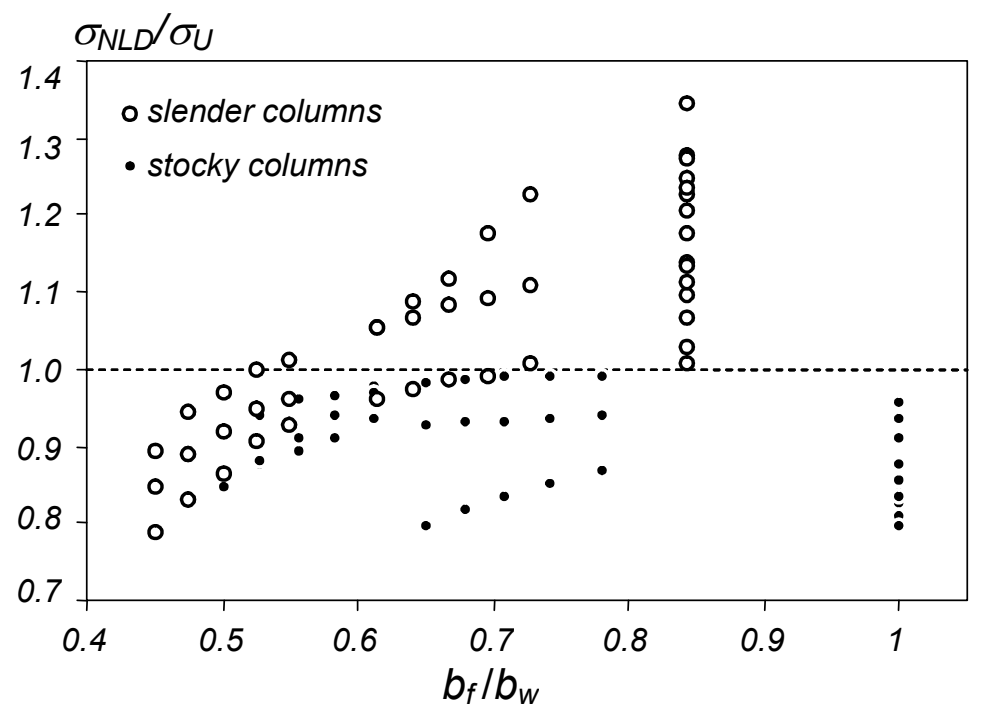

(a)
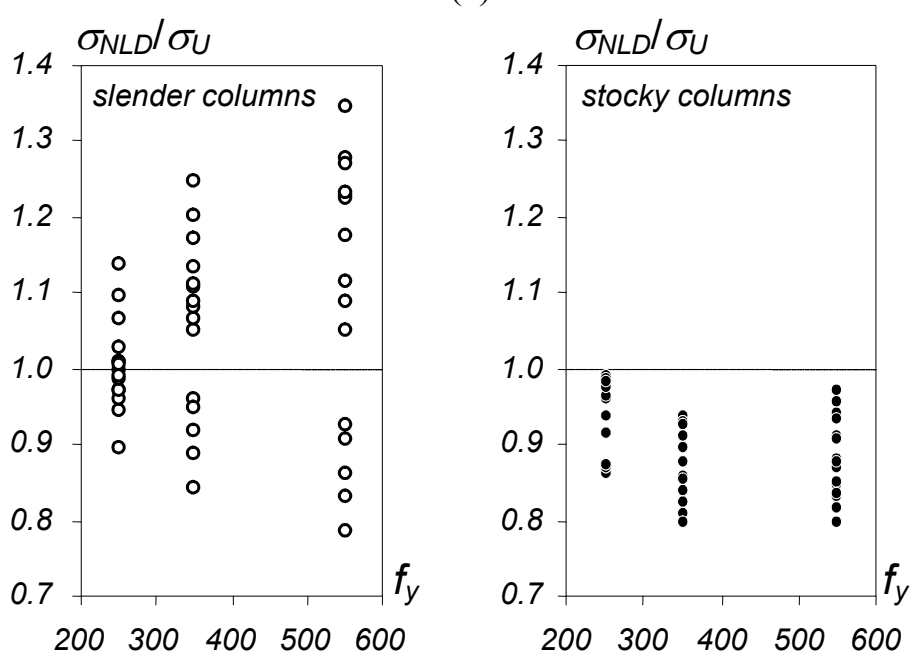

(b)

Figure 11. Variation of the Stress Ration $\sigma_{N L D} / \sigma_{U}$ with (a) $b_{f} / b_{w}$ and (b) $f_{y}$

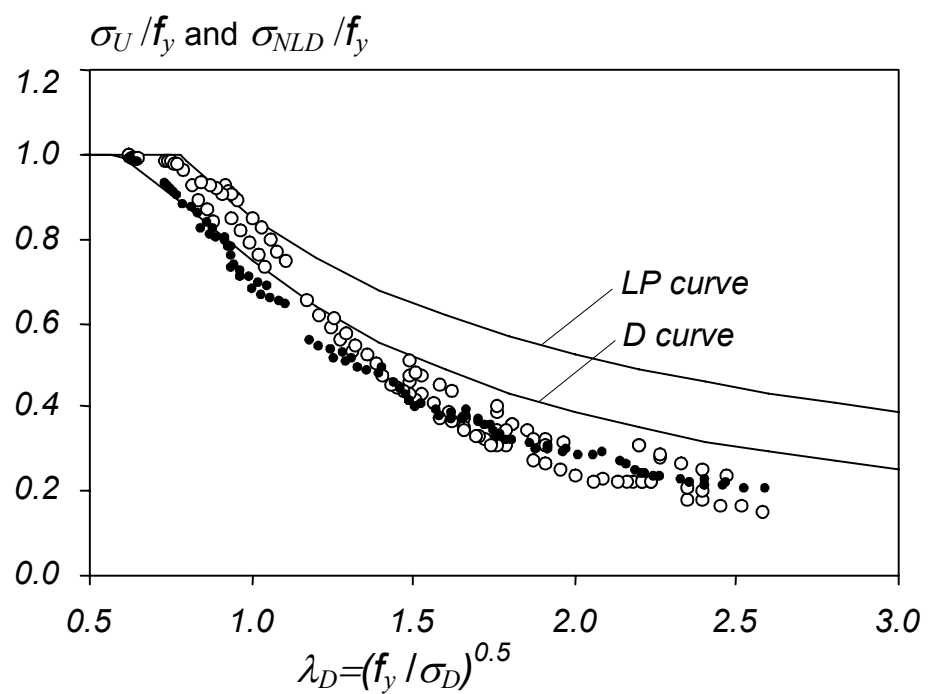

Figure 12. Variation of $\sigma_{N L D} / f_{y}$ and $\sigma_{U} / f_{y}$ with the Distortional Slenderness $\lambda_{D}$, Plus the LP and D DSM Curves 


\section{CONCLUSION}

The results of an ongoing investigation concerning the use of a DSM (Direct Strength Method) approach to estimate the ultimate strength of lipped channel columns affected by local-plate/distortional mode interaction were reported. The columns analysed (a total of 111) were all simply supported and had either low-to-moderate $\left(0.6 \leq \lambda_{D} \leq 1.4\right.$ - stocky columns) or moderate-to-high $\left(1.4 \leq \lambda_{D} \leq 2.6\right.$ - slender columns $)$ distortional slenderness - therefore, they covered the slenderness range inside which the individual local-plate and distortional DSM curves were experimentally and/or numerically calibrated and validated. On the basis of the ultimate load values obtained by means of a FEM-based parametric study, it was possible (i) to assess the performance of two basic DSM approaches that are based on the already well established expressions derived to estimate the ultimate strengths of columns failing in individual ("pure") local-plate and distortional modes, and also (ii) to identify a number of features that must be included in a more elaborate DSM approach, specifically developed to take into account the local-plate/distortional buckling mode interaction phenomenon.

Concerning the use of the two basic DSM approaches ( $N D L$ and $N L D)$ to predict the ultimate strength $\left(\sigma_{U}\right)$ of columns experiencing strong local-plate/distortional mode interaction (the local-plate and distortional critical stresses, $\sigma_{C R L}$ and $\sigma_{C R D}$, are never more than $10 \%$ apart), it was possible to conclude that:

(i) In columns with low-to-moderate distortional slenderness $\left(\lambda_{D} \leq 1.4\right)$, the $\sigma_{N D}$ values provide accurate estimates of their load-carrying capacities - i.e., the use of the existing DSM provisions for distortional buckling yields satisfactory results.

(ii) For moderate-to-high column distortional slenderness $\left(1.4 \leq \lambda_{D} \leq 2.6\right)$, the $\sigma_{N L D}$ values provide reasonably accurate ultimate strength estimates - in particular, the "quality" of these estimates is slightly superior to that of their $\sigma_{N D L}$ counterparts. However, it was noticed that the $\sigma_{N L D}$ values consistently overestimated the $\sigma_{U}$ ones in the columns exhibiting wide flanges and high yield stresses.

(iii) Nevertheless, it is fair to say that, at least for the simply supported columns dealt with in this study, the $\sigma_{N L D}$ values provide much better column ultimate strength predictions than the existing DSM provisions (for pure local-plate and distortional failures). Indeed, these values are mostly safe and fairly accurate, regardless of the distortional slenderness value, which confirms the assessment made by Yang and Hancock [10], on the basis of an experimental investigation involving lipped channel columns with "v-shape" web and flange intermediate stiffeners.

In spite of the fairly good performance of the NLD DSM approach to account for the local-plate/distortional mode interaction effects, the authors of this paper (i) are aware that further investigations are required (e.g., one must analyse fixed columns and additional experimental evidence is necessary) and also (ii) feel that there is still room for improvement, particularly for the slender columns that exhibit wide flanges and high yield stresses, i.e., the ones for which the $\sigma_{N L D}$ predictions excessively overestimate the "exact" $\sigma_{U}$ values. Therefore, the ultimate goal of the research effort currently under way is to develop, validate and calibrate (through the comparison with additional numerical simulations and experimental results) a direct strength approach that is able to cover adequately all columns affected by local-plate/distortional interactive buckling. Hopefully, this goal will be achieved for lipped channel columns in a not too distant future - some fixed column numerical results were very recently reported [24, 25] and an experimental test program is currently being carefully programmed. 


\section{REFERENCES}

[1] Schafer, B.W. and Pekoz, T., "Direct Strength Prediction of Cold-Formed Steel Members Using Numerical Elastic Buckling Solutions", Thin-Walled Structures - Research and Development (ICTWS'98 - Singapore, 2-4/12), N. Shanmugam, J.Y.R. Liew, V. Thevendran (eds.), Elsevier, 1998, pp. 137-144.

[2] Schafer, B.W., "Direct Strength Method Design Guide", AISI - American Iron \& Steel Institute, Washington DC, 2005.

[3] Schafer, B.W., "Review: The Direct Strength Method of Cold-Formed Steel Member Design", Proceedings of International Colloquium on Stability and Ductility of Steel Structures (SDSS'06 - Lisbon, 6-9/9), D. Camotim, N. Silvestre, P.B. Dinis. (eds.), IST-Press, 2006, pp. 49-66.

[4] Standards of Australia and Standards of New Zealand (SA-SNZ), Australian/New Zealand Standard on Cold-Formed Steel Structures - AS/NZS 4600 (Second Edition), Sydney-Wellington, 2005.

[5] American Iron and Steel Institute (AISI), Appendix I of the North American Specification (NAS) for the Design of Cold-Formed Steel Structural Members: Design of Cold-Formed Steel Structural Members with the Direct Strength Method, Washington DC, 2004.

[6] Schafer, B.W., "Progress on the Direct Strength Method", Proceedings of $16^{\text {th }}$ International Specialty Conference on Cold-Formed Steel Structures (Orlando, 17-18/10), R. LaBoube, W.-W. Yu (eds.), 2002, pp. 647-662.

[7] Schafer, B.W., "Advances in the Direct Strength Design of Thin-Walled Members", Advances in Structures (AsscCA'03 - Sydney, 23-25/6), G.J. Hancock et al. (eds.), Lisse, Balkema, 2003, pp. 333-339.

[8] Duong, H.M. and Hancock, G.J., "Recent Developments in the Direct Strength Design of Thin-Walled Members", Thin-Walled Structures: Recent Advances and Future Trends in Thin-Walled Structures Technology (Loughborough, 25/6), J. Loughlan (ed.), Bath, Canopus Publishing, 2004, pp. 43-62.

[9] Rasmussen, K.J. and Hossain, M.S., "Design of Slender Angle Section Beam-Columns by the Direct Strength Method", Proceedings of Fourth International Conference on Coupled Instabilities in Metal Structures (CIMS'04 - Rome, 27-29/9), M. Pignataro, J. Rondal, V. Gioncu (Eds.), Editura Orizonturi Universitare, Timisoara, 2004, pp. 331-344.

[10] Yang, D. and Hancock, G.J., "Compression Tests of High Strength Steel Channel Columns with Interaction between Local and Distortional Buckling”, Journal of Structural Engineering (ASCE), Vol. 130, Issue 12, 2004, pp. 1954-1963.

[11] Kwon, Y.B., Kim, N.G. and Kim, B.S., "A Study on the Direct Strength Method for Compression Members Undergoing Mixed Mode Buckling", Proceedings of Third International Symposium on Steel Structures (Seoul, 10-11/3), 2005, pp. 108-119.

[12] Silvestre, N., Camotim, D. and Dinis, P.B., "On the Use of the Direct Strength Method to Design Lipped Channel Columns Affected by Local-Plate/Distortional Mode Interaction", Proceedings of $4^{\text {th }}$ European Conference on Steel and Composite Structures (EUROSTEEL 2005 Maastricht, 8-10/6), B. Hoffmeister, O. Hechler (eds.), 2005, pp. 125-133.

[13] Silvestre, N., Camotim, D. and Dinis, P.B., "DSM Design Against Local-Plate/Distortional Interactive Buckling", STEEL - A New and Traditional Material for Building (ICMS'06 Poiana Braşov, 20-22/9), D. Dubina, V. Ungureanu (eds.), Taylor \& Francis, 2006, pp. 225-233.

[14] Dinis, P.B. and Camotim, D., "Local-Plate and Distortional Post-Buckling Behavior of Cold-Formed Steel Columns: Elastic and Elastic-Plastic FEM Analysis", Proceedings of SSRC Annual Stability Conference (Long Beach, 24-27/3), 2004, pp. 475-498. 
[15] Dinis, P.B.; Camotim, D., "FEM Elastic and Elastic-Plastic Analysis of the Local-Plate/Distortional Mode Interaction in Cold-Formed Steel Columns", Proceedings of Fourth International Conference on Coupled Instabilities in Metal Structures (CIMS'04 - Rome, 27-29/9), M. Pignataro, J. Rondal, V. Gioncu (eds.), Editura Orizonturi Universitare (Timisoara), 2004, pp. 477-492.

[16] Dinis, P.B., Camotim, D. and Silvestre, N., "FEM-Based Analysis of the Local-Plate/Distortional Mode Interaction in Cold-Formed Steel Lipped Channel Columns", Computers \& Structures, Vol. 85, Issue 19-20, 2007, pp. 1461-1474.

[17] Hibbit, Karlsson and Sorensen Inc. (HKS), ABAQUS Standard (Version 6.3-1), 2002.

[18] Dinis, P.B. and Camotim, D., "On the Use of Shell Finite Element Analysis to Assess the Local Buckling and Post-Buckling Behaviour of Cold-Formed Steel Thin-Walled Members", Submitted for Publication, 2008.

[19] Schafer, B.W., "Cold-Formed Steel Design by the Direct Strength Method: Bye-Bye Effective Width”, Proceedings of SSRC Annual Technical Session \& Meeting (Baltimore, 2-5/4), 2003, pp. 357-377.

[20] Schafer, B.W., "Distortional Buckling of Cold-Formed Steel Columns", AISI Report, American Iron \& Steel Institute, Washington DC, 2000.

[21] Schafer, B.W., "Local, Distortional and Euler Buckling in Thin-Walled Columns", Journal of Structural Engineering (ASCE), Vol. 128, Issue 3, 2002, pp. 289-299.

[22] Narayanan, S. and Mahendran, M., "Ultimate Capacity of Innovative Cold-Formed Steel Columns", Journal of Constructional Steel Research, Vol. 59, Issue 4, 2003, pp. 489-508.

[23] Ellobody, E. and Young, B., "Behavior of Cold-Formed Steel Plain Angle Columns", Journal of Structural Engineering (ASCE), Vol. 131, Issue 3, 2005, pp. 457-466.

[24] Silvestre, N., Camotim, D. and Dinis, P.B., "DSM Design of Fixed Lipped Channel Columns Against Local-Plate/Distortional Interactive Buckling”, Proceedings of $6^{\text {th }}$ International Conference on Steel \& Aluminium Structures (ICSAS'07 - Oxford, 24-27/7), R. Beale (ed.), 2007, pp. 752-759.

[25] Silvestre, N., Dinis, P.B. and Camotim, D., "Direct Strength Design of Fixed Lipped Channel Columns Against Multiple-Wave Local/Distortional Interactive Buckling", Proceedings of $5^{\text {th }}$ International Conference on Thin-Walled Structures - Recent Innovations and Developments (ICTWS 2008 - Brisbane, 18-20/6), M. Mahendran (ed.), 2008, pp. 281-288 (vol. 1). 